\title{
The brain as a \\ dynamically active \\ organ
}

\section{Björn Brembs}

Universität Regensburg, Institut für Zoologie - Neurogenetik, Regensburg, Germany, bjoern@brembs.net

\section{Abstract}

Nervous systems are typically described as static networks passively responding to external stimuli (i.e., the 'sensorimotor hypothesis'). However, for more than a century now, evidence has been accumulating that this passive-static perspective is wrong. Instead, evidence suggests that nervous systems dynamically change their connectivity and actively generate behavior so their owners can achieve goals in the world, some of which involve controlling their sensory feedback. This review provides a brief overview of the different historical perspectives on general brain function and details some select modern examples falsifying the sensorimotor hypothesis. 


\section{The most important question in neuroscience}

Neuroscience (or neurobiology) as Wikipedia educates us, strives to understand the emergent properties of neurons and neural circuits. The main emergent property of nervous systems is behavior: sedentary animals often have eliminated or strongly reduced their nervous systems, especially compared to ambulatory life stages (e.g. Tunicata - sea squirts), or never even evolved any, as in the Porifera (sponges). "Nothing in neuroscience makes sense except in the light of behavior. Nervous systems evolved to produce behavior. It is futile to try to understand brains without keeping this in mind" [1]. "One of the foundational aims of neuroscience is to understand behavior, in the broadest sense" [2]. "behavior-the ultimate output of the brain" [3]. "The original and still primary purpose of the brain-to endow organisms with the ability to adaptively interact with their environment" [4]. Thus, arguably, the most important question in neuroscience is whether there is a common organization to all behavior, and if so, what that organization looks like. In other words, the question of whether there is a 'grand unifying theory' of neuroscience.

Given the importance of the question, it is hardly surprising that the history of neuroscience 
is replete with hypotheses aiming to unify all behaviors under a common explanatory framework. However, the diversity of such hypotheses is relatively low. The literature is dominated by essentially two opposing hypotheses, one that sees nervous systems as passive organs (also called the sensorimotor hypothesis) and one that perceives them as active.

Early on, the concept of stimuli triggering reactions in an otherwise passive nervous system proved very attractive. In 1890, Williams James wrote that "The whole neural organism, it will be remembered, is, physiologically considered, but a machine for converting stimuli into reactions" [5]. Around the same time, two developments supported this view. One of them was Golgi's staining that showed that neurons are individual cells. Using this method, Santiago Ramón y Cajal formulated the neuron doctrine, a central tenet of which is the unidirectional conductance of activity [6]. The other discovery was that of reflex arcs. In this time, reflexes as extremely simplified forms of responses attracted the interest of researchers and, e.g., Sherrington proposed that walking was maintained by a series of interacting peripheral reflexes [7]. So popular and successful was the study of reflexes that after the pioneering work of Sherrington, Pavlov and many others, a school of "reflexology" formed [8], which thought to explain 
all, even human, behavior in terms of chains or webs of reflexes. While reflexology, at least in its radical forms, slowly faded in influence, the same concept of sensory triggered responses as the way in which all behavior is organized can be observed in later works. For instance, in 1949 Donald Hebb published his book entitled "Organization of Behavior" which received the subtitle "Stimulus and response - and what occurs in the brain in the interval between them" [9]. In some fields, this concept has become so dominant "that it is common to refer to any behaviour as a 'response' and thus by implication [...] assume that there must be an eliciting stimulus." [10]. Fifty years after Hebb, it was not unusual to find sentences in the neuroscientific literature such as "brain function is ultimately best understood in terms of input/output transformations and how they are produced" [11] or that behavior arises from "the process by which sensory stimuli are converted into motor commands" [12]. Still today, articles in prominent scholarly journals regularly contain statements mimicking the subtitle of Hebb's book: "Neuroscientists wanting to understand the brain's coding language have conventionally studied how its networks of cells respond to sensory information and how they generate behaviour [...]. But they couldn't look in detail at 
the important bit in between - the vast quantities of neuronal activity that conceal patterns representing the animal's mood or desires" [13]. Analogously, behavior can still be found defined as "the neuronally controlled, voluntary or involuntary response of an organism to its environment" [14].

In parallel, neuroscientific evidence has been accumulating which was difficult to reconcile with this passive view of nervous systems. Already while studying reflexes, it was found that abolishing them experimentally did not abolish coordinated behaviors such as locomotion [15]. This discovery of what we now call central pattern generators - neural circuits that can generate oscillatory activity in the absence of any stimulation - challenged the notion of nervous systems being passive organs [16]. Using the then newly developed EEG method, Berger found that "mental work [.. adds only a small increment to the cortical work which is going on continuously and not only in the waking state"' [17]. While 'pacemaker' neurons - neurons firing spontaneously, without requiring synaptic input - were hypothesized to exist for quite some time, it wasn't until the 1960s that spontaneously firing neurons were actually discovered [18]. Whereas these 'pacemaker' neurons fire either tonically or rhythmically, we now know that neurons can also show arhythmic, 
probabilistic spontaneous firing patterns, consistent with nonlinear dynamics $[19,20]$. The central aspect of feedback loops for controlling environmental stimuli and thus achieving goals was also recognized early on [21]. One particularly attention-grabbing event questioning the passivity of nervous systems was the 1973 Nobel Prize to the three ethologists von Frisch, Lorenz and Tinbergen "for their discoveries concerning the organization of behavior", discoveries "made in animals but applicable to man [sic]". Lorenz described the main insight of their work in his autobiography: "The most important break-through of all our attempts to understand animal and human behaviour [was] the recognition [...] that the basic central nervous organisation consists of [...] permanently producing endogenous stimulation." In these writings, an alternative concept emerges, that of a dynamically active nervous system.

Given the dominance of the passive inputoutput concept, the proponents of the active concept directly opposed the idea of a passive nervous system: "But the nervous system is primarily a device for generating action spontaneously. It's an ongoing affair. The biggest mistake that people make is in thinking of it as an input-output device." Graham Hoyle (quoted in [22]. The critiques 
of the passive concept are numerous: the stimulus-response doctrine "is incomplete in an important way, leading brain sciences toward apparent mysteries where none actually exist" [23]. The concept of central pattern generators was expanded to the human cortex [24]. Arguing from energy expenditure, Marcus Raichle espoused an active-dynamic view of brain function, where ongoing, intrinsic activity is a hallmark: "the majority of brain energy consumption is devoted to functionally significant intrinsic activity". Raichle also noted that "the number of synapses [...] devoted to incoming [sensory] information is less than $10 \%$ of the total number of synapses" [25]. Consistent with the latter emphasis on central processing, visual perception in monkeys has been found to be crucially dependent on intrinsic cortical activity [26]. In 2014, summarizing several decades of neuroscience in the fruit fly Drosophila, Martin Heisenberg wrote, "What's the problem with brain research? The problem is the inputoutput doctrine. It is the wrong dogma, the red herring" [27]. Recently, a trend away from the passive stimulus-response concept has been indicated: "the focus now shifts away from stimuli, [...] to the brain itself, that is, its own dynamics. The early sensory-motor and current cognitive views of the brain are now complemented and, as 
we suppose, integrated within the larger framework of a dynamic view of the brain" [28].

\section{Orthogonal perspectives}

For a freely moving organism, its behavior is in constant interactions with the environment as the feedback loop is closed (Fig. 1a). The behavior of the organism controls which stimuli it will perceive and these stimuli instruct the organism which behavior to select next. Because there are at least two processes to consider, study and understand in this situation, it is tempting to attempt to open the feedback loop, if only conceptually, and consider just one of the processes.

This conceptual split yields a dichotomy between two orthogonal perspectives that is reflected in the literature cited above. The dominant, passive perspective emphasizes the instructive properties of the environment and holds that stimulus and response are neuronally coupled such that any internal (i.e., cognitive) processes merely serve to modulate the sensorimotor coupling (Fig. 1b). Clearly, this approach has proven scientifically very productive. The second, active perspective emphasizes the control that behavior exerts over the environment and purports that intrinsic processes are the primary driver of behavior, and that external stimuli merely serve to 
modulate this cognitive process of generating actions (Fig. 1c). This distinction was first drawn up by Thurstone in 1923 [29].

A less obvious corollary of this dichotomy is that there is an additional distinction between the two perspectives that cannot be readily captured in a figure: the passive perspective holds that the brain is static with ongoing fluctuations playing a subordinate role (if they are not considered noise), while the active perspective entails constant, ongoing dynamics at the heart of the functioning principle. In mathematical terms, while the passive concept can be modeled with simple linear equations, the active concept requires dynamical systems theory and nonlinear modeling [30,31]. A brief look into the first chapter of contemporary neuroscience textbooks reveals a static image of either a reflex circuit as representative of all circuits or a more schematic representation of the brain as a passive-static organ, merely 'relaying' information from our sensory organs to our muscles [32](Fig. 1d). 


\section{A) Closed feedback loop}

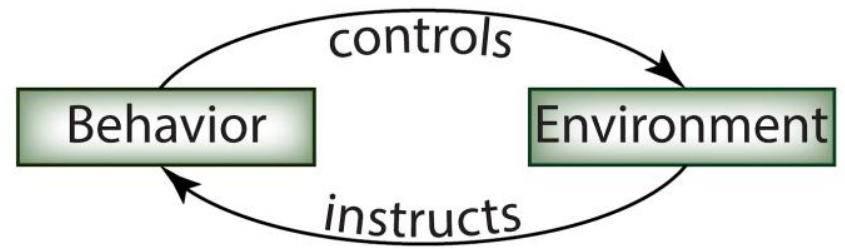

B) Passive-static perspective

C) Active-dynamic perspective
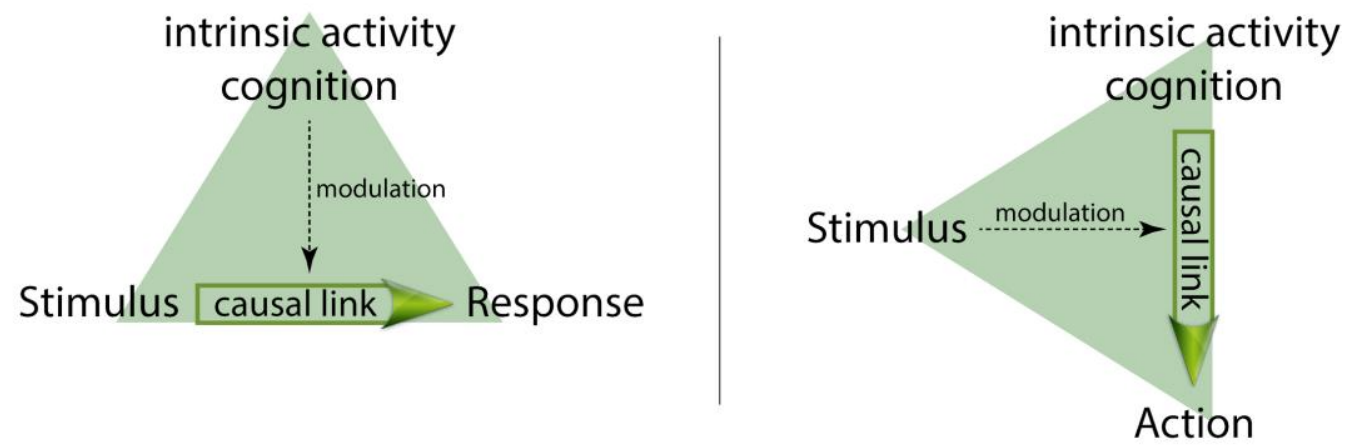

D) Textbook perspective
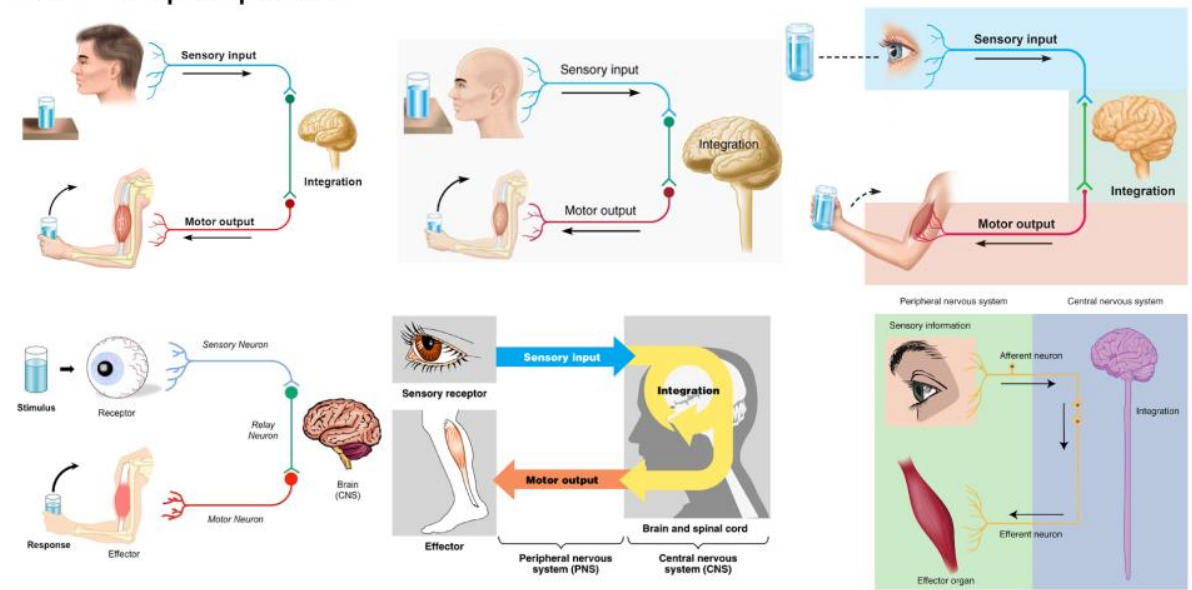

Fig. 1: Different perspectives on brain function

A, Freely moving animals control their sensory input with their behavior and the perceived feedback from the environment instructs them which actions to select next in order to achieve their goal (goal-directed behavior). This closed-loop situation complicates clear statements about cause and effect in neuroscience, leading to attempts to open the loop for linear analysis. B, Opening the closed feedback loop at the behavior of the animal presupposes that the main causation needing understanding is one from the environment to the behavior. It assumes that nervous systems are organized mainly in a passive way, such that external stimuli are both necessary and sufficient causal antecedents for behavior. Active internal processes, inasmuch as they play a role in this perspective at all, at most modulate the response to external stimuli. C, The goal-directed nature of behavior is largely preserved in the active-dynamic perspective, where internal processes generate actions in order to control the stimuli the organism will encounter. If present, stimuli modulate the generation of behavior, but are neither necessary nor sufficient for any given behavior to be generated. D, Six arbitrarily selected examples from neuroscience textbooks schematically depicting the passive-static perspective on nervous system function. B, C: Original idea: Bertram Gerber, Magdeburg, Germany 


\section{Classifications}

The orthogonality of the two concepts illustrates that the ongoing debate revolves around the primary causal origin of behavior: is the main contributor to the behavior selection process external or internal? One may argue that this discussion is irrelevant as natural behavior always occurs in a closed feedback loop between the organism and its environment and the two perspectives are mere two sides of the same conceptual coin (Fig. 1a). In this view, the distinction between actions and responses is purely semantic and the different classifications superfluous. However, as the work of Pavlov has demonstrated, which part of the loop we decide to open for linear scientific analysis is crucial for the kind of experiments we are going to design. Open-loop and closed-loop experiments can yield dramatically different biological results, even if the tasks appear to be otherwise entirely equivalent [33]. The nomenclature according to which science classifies objects and phenomena influences our thinking about them and hence our experimental design. This is the case for all of science and a prominent recent example is astrophysics: after Pluto was classified as the ninth planet of our solar system in 1931, it attracted so much attention that it took until 2006 before the other, similar sized trans-Neptunian 
objects were discovered. Classifying Pluto as a planet has, by virtue of the connotation that planets clear their orbit of other objects, delayed the astrophysics of our solar system by decades [34].

The classification of objects, processes and phenomena hence has far-reaching consequences for how scientists think of them and, consequently, what kind of experiments they design. The debate centered on whether nervous systems are best characterized as passive or active thus decides which direction neuroscience is going to take [35]. Above and beyond possible future trends in neuroscience, an article entitled "The Crisis in Neuroscience" specifically pointed out that "methods used to analyze input-output systems are not only inadequate for understanding circular causation; they can produce misleading results" [36].

Despite now more than a century of accumulating evidence challenging and contradicting the notion of nervous systems passively responding to external stimuli, most experimental neuroscience research is still dominated by experiments designed from a passive-static perspective $[37,38]$. For such experiments to yield reproducible results, they are commonly designed to minimize the role of intrinsic neural activity which is 
seen as a source of noise which needs to be eliminated to achieve a high enough signal to noise ratio. Collectively, especially in mammals, many of these intrinsic processes have often been referred to as 'cognition'.

\section{Cognition}

Not everyone agrees on what is to be understood by the term "cognition" [38-40]. As cognition, in its neuroscientific sense, refers to a process, the latin verb cognoscere, meaning to think, learn, know, realize or become aware of something, can provide us with a starting point for a scientifically useful definition. From this etymology, it appears as if the term ought to be used to describe internal processes. Consistent with this understanding, the term has often been used to contrast it with the processing of external stimuli [40]. The so-called "cognitive revolution" [41-48], for instance, sought to scientifically investigate such internal processes after decades of dominant behaviorism for which such a peek into the 'black box' of the brain was considered unnecessary, even futile.

Thus, both etymologically and historically, it makes sense to use the term 'cognition' to contrast it with processes that are mainly concerned with processing sensory stimuli while they are 
present and linking them to their appropriate responses without requiring any additional internal processing (even though this sensory processing may be very complicated, [40]). In this understanding, cognition describes active processes that (can) take place in the absence of external stimuli $[40,49,50]$, while non-cognitive processes are passive and need external stimuli to trigger them. It is also not uncommon to ascribe such active cognition mainly to humans, perhaps primates, while other animals are thought to operate according to more passive input-output rules (but note the difference between cognition and agency [51]). Another one of the many uses of the term 'cognition' (and perhaps the most widely used?) places the internal processes between the external stimuli that trigger them and before a behavioral response becomes observable, i.e., the process that converts perceptions into action plans (see Fig. 1d)[23,32,36]. This concept makes it nearly impossible to distinguish cognition from non-cognitive sensory processing or response preparation, strongly curtailing its usefulness: how many neurons after the sensory neurons does cognition start and how many synapses before the motor neurons or muscles/effectors does it end? Indeed, on the neuronal level, the cartoonish (Fig. 1D) distinction between perception, integration and action dissolves [4]. Perhaps 
the recent broadening of the use of 'cognition' is indicative of this demarcation problem [39].

Using the term 'cognition' to describe intrinsic processes that (can) take place in the absence of stimuli, allows us to distinguish the two types of concepts described above by the role cognition plays in them. Responses to external stimuli are behaviors where cognition, if present at all, merely acts as a modulator (Fig. 1b). Actions emitted by the animal without a fixed relation to antecedent stimuli are behaviors where cognitive processes are the causal reason for generating or selecting the behavior (Fig. 1C). Following this logic, many if not most experiments in neuroscience seek to minimize the influence of cognition (unless the goal is to explicitly study cognition).

It appears as if the success of studying behaviors coupled to antecedents may have caused us to overlook the possibility that these behaviors may not reveal much insight into general brain function. The following examples serve to remind the reader that even when going to extreme lengths to minimize intrinsic activity, the perspective of a passive-static nervous system remains difficult to defend, today more so than ever before. 


\section{Reflexes as extreme responses}

Reflexes are commonly thought of as extreme examples, but nonetheless representative of how behavior is organized more generally: a passive-static system, triggered by external stimuli. Importantly, as the reflex arc is known, it is thought that cognitive processes do not play any role in the function of the reflex arc. Today, we know more about reflex arcs and their seemingly few neurons than about any other class of behaviors. Many if not most of both our school as well as university textbooks still introduce reflexes either as the simplest forms of behaviors or even as the ancestral behavior from which all other behaviors evolved [32]. This is despite the wealth of evidence that reflexes are neither simple nor ancestral, let alone representative of most other behaviors in their input-output structure.

\section{H-reflex conditioning}

Textbook reflexes such as the classic kneejerk reflex are often depicted as consisting of only two neurons, a sensory neuron and a downstream motor neuron (Fig. 2). A classic, minimal input-output system. 


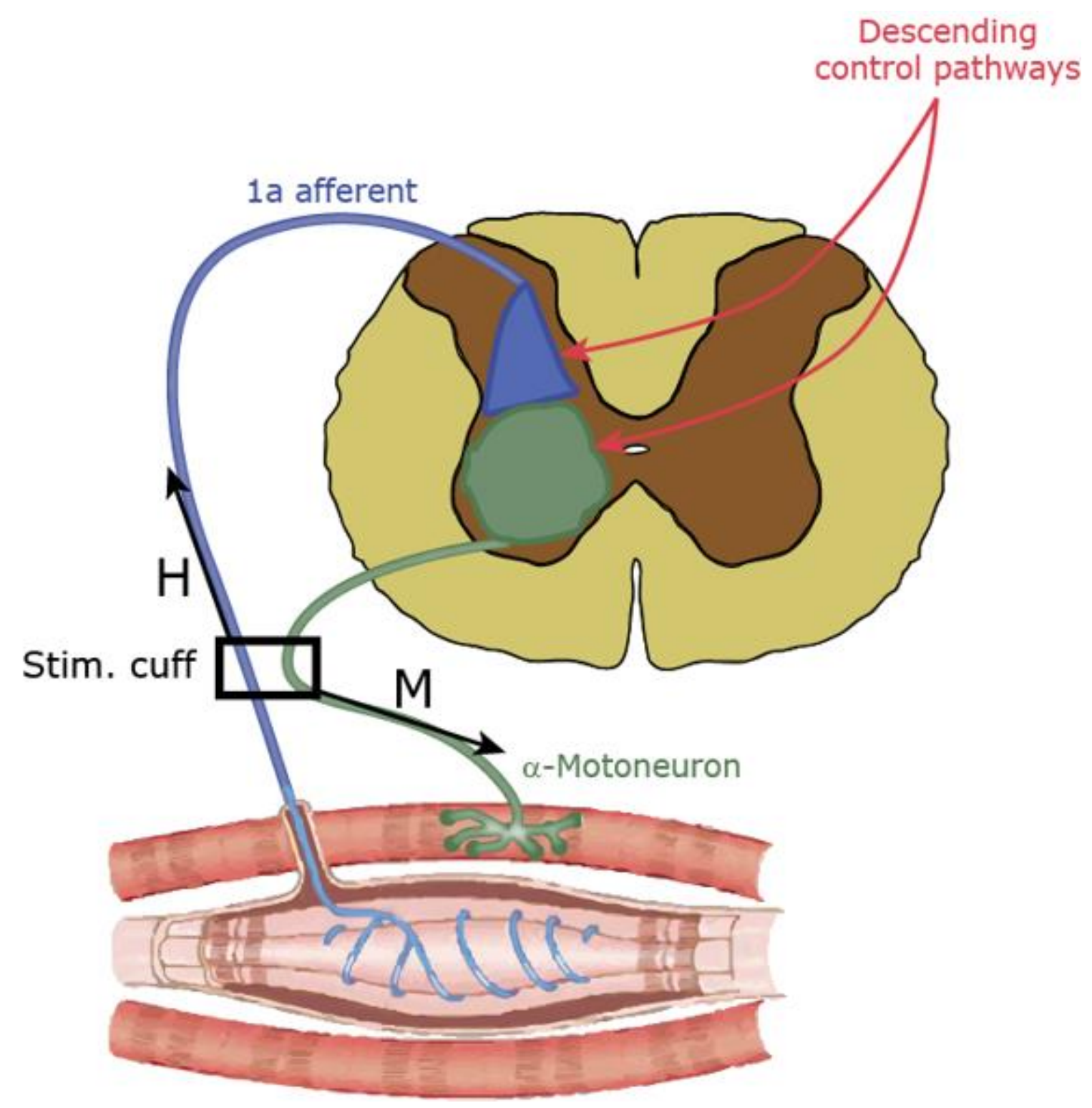

Fig. 2: Sketch of spinal stretch reflex with cuff electrode

Schematic representation of 1 a sensory neuron (blue, cell body not shown) with a synaptic connection to the alpha motorneuron (green). In a stretch reflex, the spindle of the sensory neurons detects the muscle stretch and excites the motorneuron which leads to a contraction of the muscle. Descending control pathways (red) from the brain and spinal cord provide synaptic input varying the amplitude of spinal stretch reflexes. Stimulating the nerve containing both sensory and motor fibers with a cuff electrode (black), leads to a fast contraction recorded as the 'M-Wave' in an electromyogram, while the 'H-wave' is delayed due to the longer conduction length via the sensorimotor synapse. 
A 1 a sensory neuron innervates the muscle with a spindle and senses the stretch in the muscle. In the spinal cord, it makes a monosynaptic connection to an alpha-motorneuron which contracts the muscle. A simple experimental manipulation allows for a controlled stimulation of this reflex. Precisely reproducible stimulation is passed to the reflex arc via a cuff electrode, placed around the spinal nerve comprising both sensory and motor fibers. An electromyogram (EMG) records the contractions of the muscle. Stimulation via the cuff electrode leads to two signals in the EMG, the early M-Wave, mediated by the direct stimulation of the motor neuron by the electrode and the later H-Reflex, mediated by the synaptic connection between the stimulated sensory neuron and the motor neuron.

With this preparation one can now elicit the H-Reflex with always the exactly identical stimulation and measure the reflex amplitude with high precision. If one now stimulates the cuff electrode several times a day over weeks in experimental animals such as mice, rats or monkeys, the reflex amplitude shows considerable variability that arises from a number of disparate sources. As if the variability itself wasn't already surprising enough, it has been shown that this variability cannot be dismissed as mere noise. In fact, this variability is the main function by which 
the reflex operates and without which none of the studied animals (and humans) could walk properly [52-75].

The many sources of this variability are both intrinsic to the reflex and arise from descending control pathways (Fig. 2), originating in different brain areas. Interestingly, already the $1 \mathrm{a}$ fibers themselves are spontaneously active even at rest [76]. Superficially, it may seem as if this connectivity mimics closely the passive-static organization (Fig. 1b), with intrinsic processes modulating the reflex. However, this variability is central and not peripheral to the function of these reflexes, as we will see. The evidence for this centrality comes primarily from studies where the variability was used to operantly condition the $\mathrm{H}$ Reflex. In such experiments, half of the experimental animals were rewarded with food whenever the amplitude of their H-Reflex was above baseline and half of the animals were rewarded for below-baseline H-Reflex amplitudes. In the course of such training, the animals which were rewarded for larger H-Reflex amplitudes increased their responses up to approximately double while the animals rewarded for smaller amplitudes decreased theirs up to about half.

Such plasticity is remarkable in its own right for such a supposedly simple system and on 
its own raises doubts about the hypothesis that reflexes are simple input-output systems, responding always with the same response to the same triggering stimulus. However, when studying the more general consequences of the conditioning, it becomes clear that the input-output concept is at best superficial and at worst not even false. Observing the gait of the conditioned animals, it was suspicious that they did not appear to limp or exhibit any other gait-related abnormalities. This was surprising because these reflexes are engaged at every step and make coordinated locomotion possible. More detailed study of the animals revealed compensatory plasticity in the other legs to ensure the gait of the animals was not affected by the change in reflex amplitude of one particular joint in one leg.

\section{Spinal stretch reflexes are active output-input sys-}

\section{tems}

These results demonstrate that the actual mode of operation of stretch reflexes is actually the opposite of an input-output system, despite, at first, appearing to match a passive-static system (Fig. 1b) perfectly: during walking, at every step when the reflex is elicited, a small change in amplitude is eliciting a response from the environment of the reflex providing feedback as to the effectiveness of the reflex in controlling gait. 
The reflex generates an output (a change in amplitude) and evaluates re-afferent feedback to adjust the reflex-amplitude to current walking conditions. Reflexes are thus output-input systems, generating spontaneous output (a change in amplitude) and evaluating the consequences of these probing actions, reminiscent of trial and error problem-solving. As much of this spontaneous variability is not related to environmental stimuli, the definition of cognition above would include such internal generation of spontaneous behavioral activity as a cognitive process. Thus, reflexes do not seem to serve as good examples of the stimulus-response concept, rather the opposite. This is a case where the connectivity of the circuit may look deceivingly similar to a passivestatic system (Fig. 1b), but studying its function, it becomes clear that it constitutes an active-dynamic system (Fig. 1C).

This adaptive, cognitive component in behaviors as extreme as stretch reflexes not only challenges the notion that reflexes can be classified as 'responses' at all, it also begs the question how one can classify less extreme behaviors as responses? Surely, as soon as more neurons are involved, a behavior can only become less response-like and contain more 'cognitive' components? 


\section{Other responses}

Perhaps the approach of studying numerically simple behaviors such as reflexes to understand stimulus-response relationships is wrongheaded: given the variability in these behaviors, it is clear that no fixed input-output relationship exists that could be studied. The influence of descending inputs into the reflex arc is simply too dominant. Therefore, one ought to, instead, study behaviors with less variability and more readily observable stimulus-response coupling. There are several classes of such behaviors that one could try to study and I selected three examples that lend themselves as particularly instructive.

\section{Insect phototaxis}

Few behaviors stand out as so rigid and stereotypic as the proverbial moth flying into the flame. Insect phototaxis is probably the most iconic behavior to exemplify the concept of stimulus and associated response also outside of academia. Insects in the dark appear irresistibly drawn to any light source and even to non-scientists the many dead insects at lamp posts appear to indicate that there appears to be little flexibility in this behavior. Insect phototaxis thus appears to be an excellent candidate to study how sensory 
input is converted into a response with very little, if any, cognitive influence.

However, it has been known for more than a century that phototaxis is not as rigid as it may appear at first glance. For instance, if Drosophila fruit flies are confined in a small glass tube oriented towards a light source, they walk towards the light source. However, it was described in 1918 that this tendency is much reduced if the wings of the fly were shortened [77]. Subsequent research not only confirmed these results, it also suggested that this flexibility arises from mechanisms related to valuation that modulate the attractiveness of a light source [78]. It appears as if the flies evaluate their flying ability and adjust the attractiveness of light or dark stimuli accordingly. This valuation mechanism may have evolved to guide the animal's decisions in the vulnerable time right after eclosing from the pupal case, when the exoskeleton of the animal is still soft and the wings not yet expanded. During this time, the animals also show negative phototaxis that only disappears once the animal has developed its ability to fly.

It thus seems that insect phototaxis also contains significant components of internal processing and perhaps even some form of metacognition, an 'awareness' or evaluation of what 
the animal is capable of doing before it embarks towards or away from a light source. Even in such seemingly stereotypic behaviors as insect phototaxis, the internal state of the animal appears to be a better predictor of the animal's behavior than the supposedly behavior-eliciting stimulus. These results corroborate earlier observations by, e.g., S. Benzer, who mentioned in an interview that "... if you put flies at one end of a tube and a light at the other end, the flies will run to the light. But I noticed that not every fly will run every time. If you separate the ones that ran or did not run and test them again, you find, again, the same percentage will run. But an individual fly will make its own decision" (cited by [79]). The observation mentioned in this interview was later replicated in our laboratory [80].

In light of these data, it is straightforward to hypothesize that both spinal stretch reflexes and insect phototaxis are unsuitable examples for the broad generalizability of the stimulus-response concept, because they are not coupled to evolution tightly enough. Without sufficient selection pressure, there is no need to optimize the trait in question and so a large amount of variability is to be expected. Following this line of argument, escape behaviors and feeding behaviors ought to be among the most optimized stimulus- 
response behaviors as they would be most tightly coupled to the survival of the animal.

\section{Predictable escape responses}

Perhaps the most well-known and beststudied escape response is the C-start response in teleost fish. Mediated by the equally wellknown Mauthner cell, the largest vertebrate neuron, it heads the fish away from a threatening stimulus [81-96]. Sensory neurons in the inner ear or the side-line organ synapse onto the Mauthner neuron which leads to contraction of the contralateral trunk muscles and inhibition of the ipsilateral ones to bend the animal into a Cshaped form with the head pointing away from the stimulus (Fig. 3). 

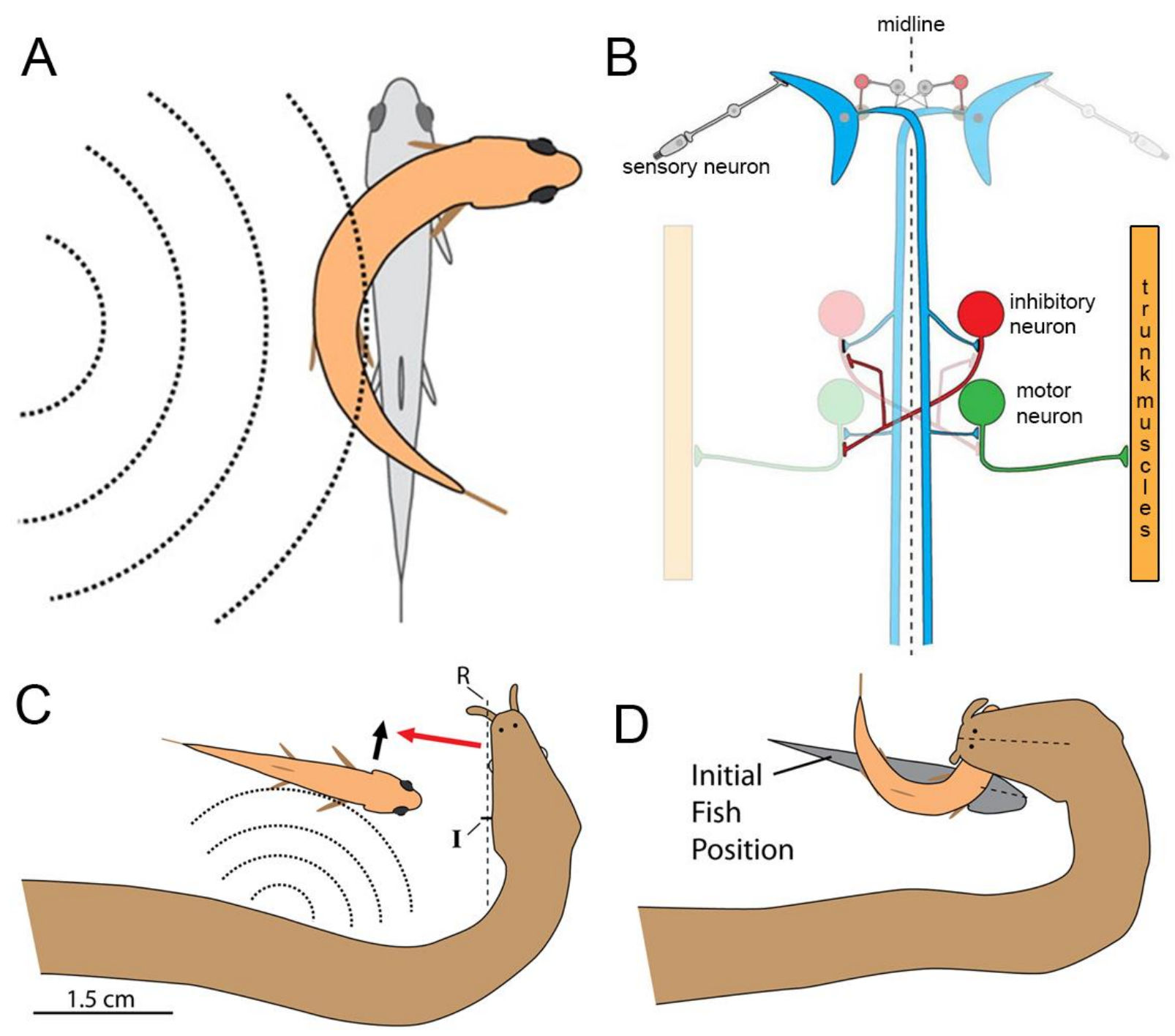

Fig. 3: Teleost C-Starts and the Mauthner neuron

A, Fish bend their body into a C-shape in response to some mechanosensory stimuli, such that they are heading away from that stimulus. B, Schematic depiction of the connectivity of the C-start escape circuit. The inner ear or sideline sensory neurons make connections to the Mauthner cell (blue), which, in turn, excites contralateral motor (green) and inhibitory (red) neurons. The excitation of the contralateral motor neuron (green) leads to the contraction of trunk muscle which bends the fish into the C-shape. C, When hunting, Tentacled snakes ambush their prey by assuming a Jshaped posture and triggering the C-Start with a distal part of their body. D, The CStart propels the fish directly into the mouth of the snake (adapted from [97]). 
C-starts are highly evolved behaviors, optimized for speed and usually save fish from predators, which is why most teleost fish carry this trait. Arguably, there is a very strong selection pressure on the speed and hence efficacy of this behavior. This behavior is also mediated by a very small number of neurons and synapses, reducing its complexity. Finally, this behavior is highly stereotyped: unlike stretch reflexes, these responses are highly reproducible from trial to trial and even between animals. However, it is precisely this stereotypy which makes generalizing anything from this behavior to other behaviors so difficult.

While reproducibility is always an advantage for laboratory study, such predictability is a risky strategy and rarely evolutionary stable. In the case of C-starts, there exists a fully aquatic snake species, the south-east Asian Tentacled Snake (Erpeton tentaculatum). These snakes feed exclusively on fish by exploiting their C-start responses [97-99]. The snakes are sit-and-wait predators bending into a typical j-shaped form that allows them to use the distal end of the J to startle the fish directly into the snake's mouth. Clearly, if all behaviors were so predictable, the animals displaying them would not be alive for long. Such extremely predictable behaviors can 
only remain in the gene pool if both the behavior is an exception and the exploiting species is rare.

This phenomenon of exploited predictable responses has been observed in other species as well. Like the C-starts of teleost fish, the jump responses of dipterans are also mediated by a wellstudied giant fiber system [100-111]. A bird species, painted redstarts (Myioborus pictus), uses visual displays to trigger the escape response in their dipteran prey in order to overcome the flies' camouflage and capture them when airborne and clearly visible against the bright sky $[112,113]$.

Humans exploit the escape behavior of worms to their mole predators by re-creating the sounds of burrowing moles in a technique termed "worm-grunting" [114,115]. Highly reproducible behaviors such as those cited above are exquisitely amenable to laboratory study and much of our knowledge in neuroscience rests on the generalizations made from such laboratory experiments. However, if experimenters can reproducibly elicit the behavior in a laboratory, so can, arguable, competitors, predators or prey of that species. Predictability is not an evolutionary stable strategy and hence these behaviors do not lend themselves easily as generalizable models for other behaviors. 


\section{Unpredictable escape responses}

This becomes obvious when looking at other escape behaviors in different species. In both cockroaches and frogs, the same escape response-eliciting stimuli cause the animals to escape in different directions for every stimulus presentation [116-119], similar to each stretch stimulus leading to different reflex amplitudes. In the case of stretch reflexes, amplitude variability ensures proper gait, in escape responses, directional variability ensures unpredictability and, hence, survival. Studies comparing escape strategies in rodents have also observed varying degrees of unpredictability and were able to relate increased unpredictability to increased survival and habitat choice $[120,121]$.

In some species with giant neurons mediating escape behavior such as crayfish and their tail-flip responses, some of this unpredictability and flexibility is mediated by additional circuits also controlling the same escape behavior musculature [122]. In these cases, what to a human observer appears as two identical tail-flips, may have been mediated by two entirely separate neuronal circuits. These results suggest that identical stimuli can lead to rapidly diverging neuronal firing patterns, an observation starkly at odds 
with the picture of a passive-static nervous system detecting a stimulus and then reacting in always the same way to the same stimulus in a machine-like manner.

Several species have evolved their escape strategies to incorporate different behaviors and not just unpredictable variations of the same escape response. For instance, internal states such as hunger or walking speed, knowledge about aspects in the environment such as shelters or other desirable resources modulate action selection between freezing and escape [123]. All of these observations show that even escape behaviors most often combine information from various sources before deciding on an adaptive source of action. The environment is only one of these information sources guiding adaptive action. There are thus many different ways in which always the same, identical stimulus can be followed by highly divergent actions.

In the medicinal leech, Hirudo medicinalis, we are getting a glimpse into the neural mechanisms of how identical stimuli can lead to rapidly diverging neural activity. Isolated leech nervous systems can generate spontaneous, coordinated neural activity that would lead to locomotor or escape behaviors such as crawling or swimming if the rest of the animal were still intact. They are 
able to initiate such motor programs ('behavior') in the dish, when all sensory organs have been dissected away, which is a remarkable capacity in its own right. More relevant to the current question, these isolated nervous systems can also respond with such coordinated activity to electrical stimuli mimicking touch to the skin [124,125], which would lead to the intact animal locomoting away from a noxious stimulus ('escape'). If such stimulation is applied appropriately, always the same stimulus to always the same nerve elicits crawling patterns in some trials and swimming patterns in other trials (Fig. 4). 
A

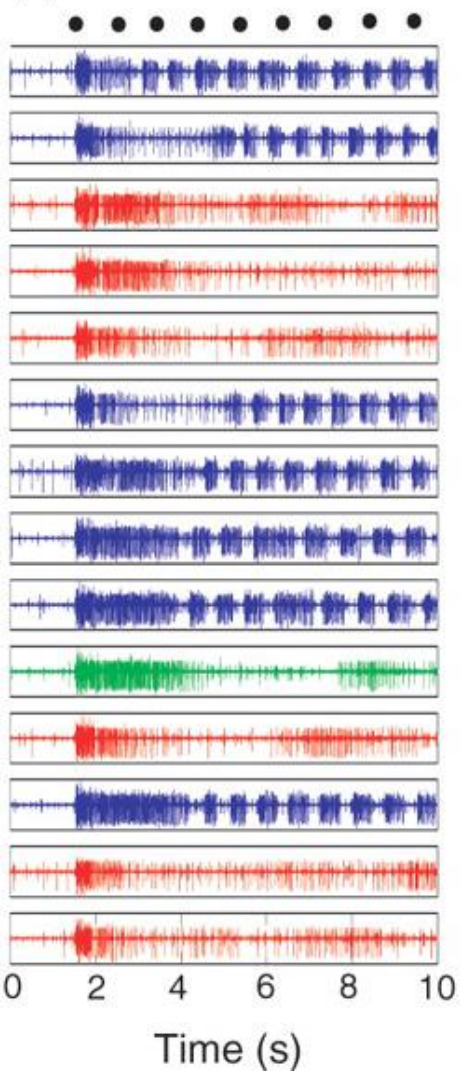

B

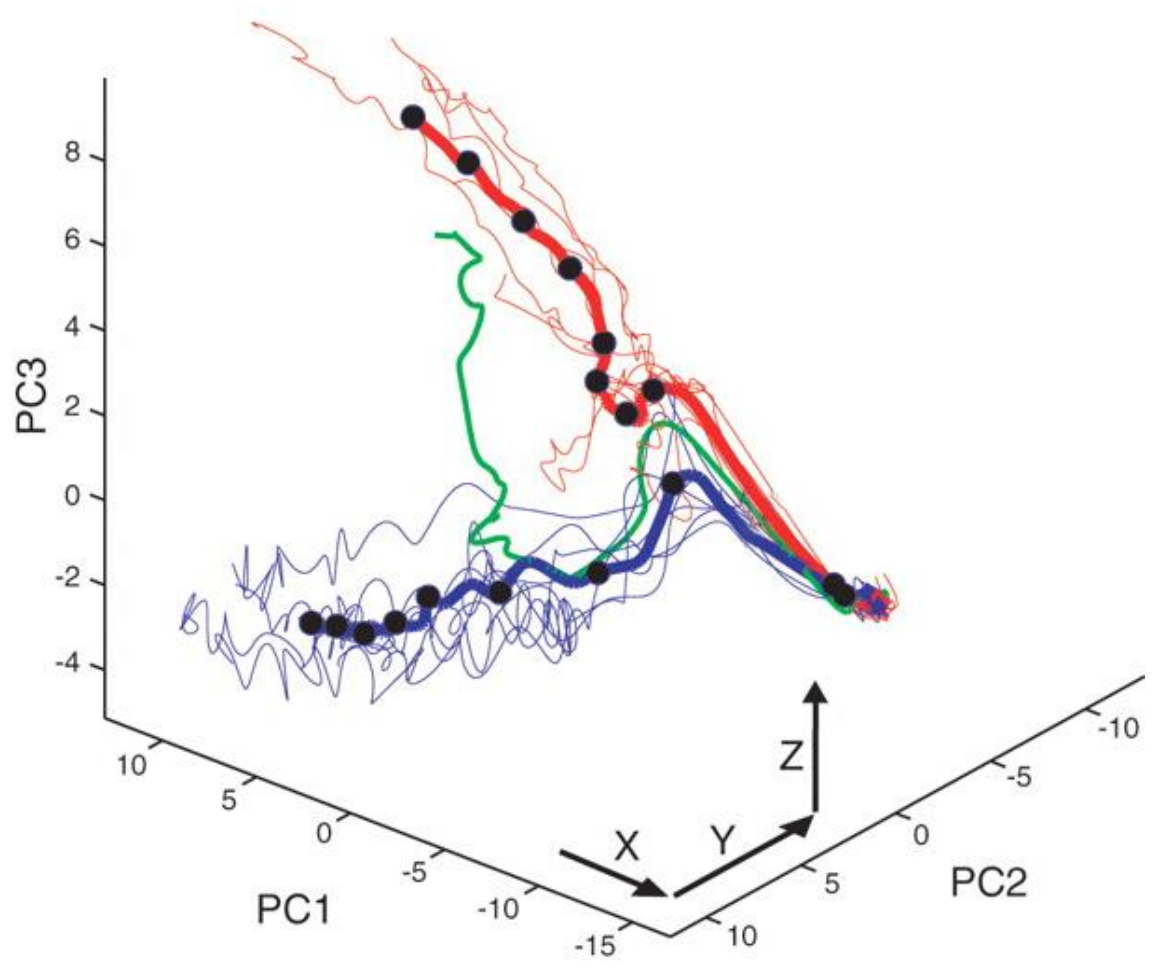

Fig. 4: Neuronal state space of leech decision-making

A, Nerve recordings indicating the 14 decisions of an isolated leech nervous system to generate swimming motor patterns (blue) or crawling motor patterns (red) after a nerve stimulation mimicking mechanosensory stimulation. Green - intermediate pattern. B, Reconstructed and dimensionally reduced state space derived from recording from 143 neurons after each stimulation. Neural activity in the leech ganglion starts in a similar (resting-)state before each stimulation and then quickly diverges in the process of decision-making (adapted from [124]).

Recording from all neurons in a leech ganglion, it is possible to reconstruct a state space reduced into three dimensions and follow the ganglion on its walk through state space over time (Fig. 4). What emerges is an image of each trial 
starting on a trajectory similar to all other trials, but then quickly diverging towards the swimspace or the crawl-space. Such behavior is consistent with the dynamics of nonlinear systems: at first, nearby parameter sets evolve similarly, only to later diverge exponentially. One can also see a second hallmark of nonlinear systems in the leech data: basins of attraction or multistability. The walks through state space are not random even though they show a high degree of variability. The walks, instead, roughly seem to follow tracks that can be distinguished as swimming or crawling in the nerve recordings. These are all very familiar properties known from dynamical systems theory and evince a highly dynamical system, pushed by external stimuli sometimes into this basin of attraction, sometimes into the other. This image is starkly at odds with the passive-static input-output concept still prevalent in neuroscience.

In summary, escape responses are either so uniquely and extremely stereotypic and predictable, that it is impossible to generalize from them to other escape responses, let alone behavior more generally. Or they contain the same 'cognitive', endogenous components that already put the suitability of stretch reflexes as general models of the stimulus-response concept in doubt. Thus, in conclusion, escape responses can also be 
dismissed in search for a class of behaviors that can serve as examples for the generalizability and usefulness of a stimulus-response concept for the organization of behavior.

\section{Feeding behavior}

Similarly essential for survival as escape behaviors are feeding behaviors. If the stimulusresponse concept is a useful approach to the understanding of behavior, the input-output organization of behavior ought to be particularly apparent in feeding behaviors, selected to maximize nutrient intake. A neuroscientifically particularly well-studied feeding behavior is that of the marine snail Aplysia. 
A

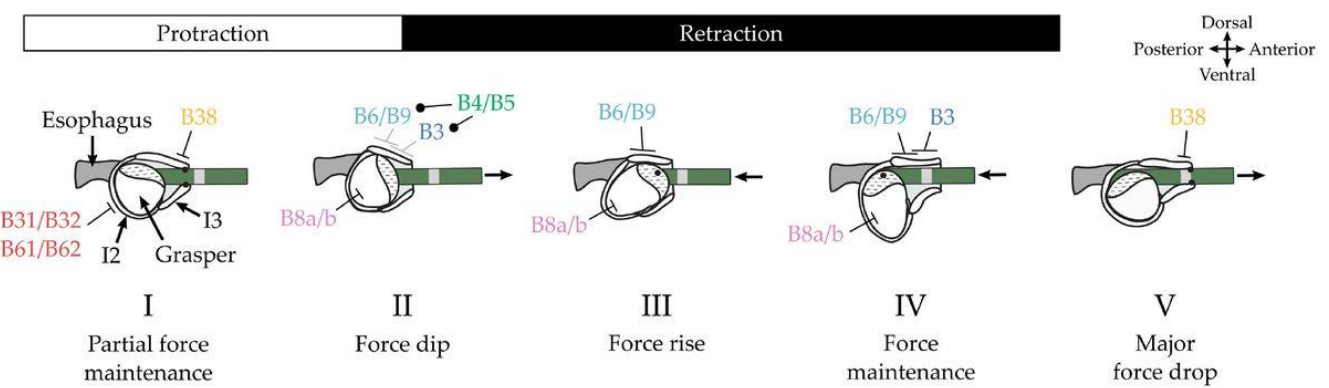

B1 Unloaded

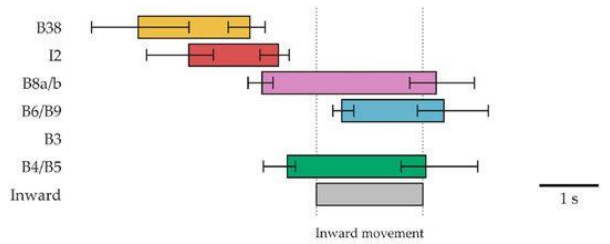

B2 Loaded

\section{C1 Unloaded}
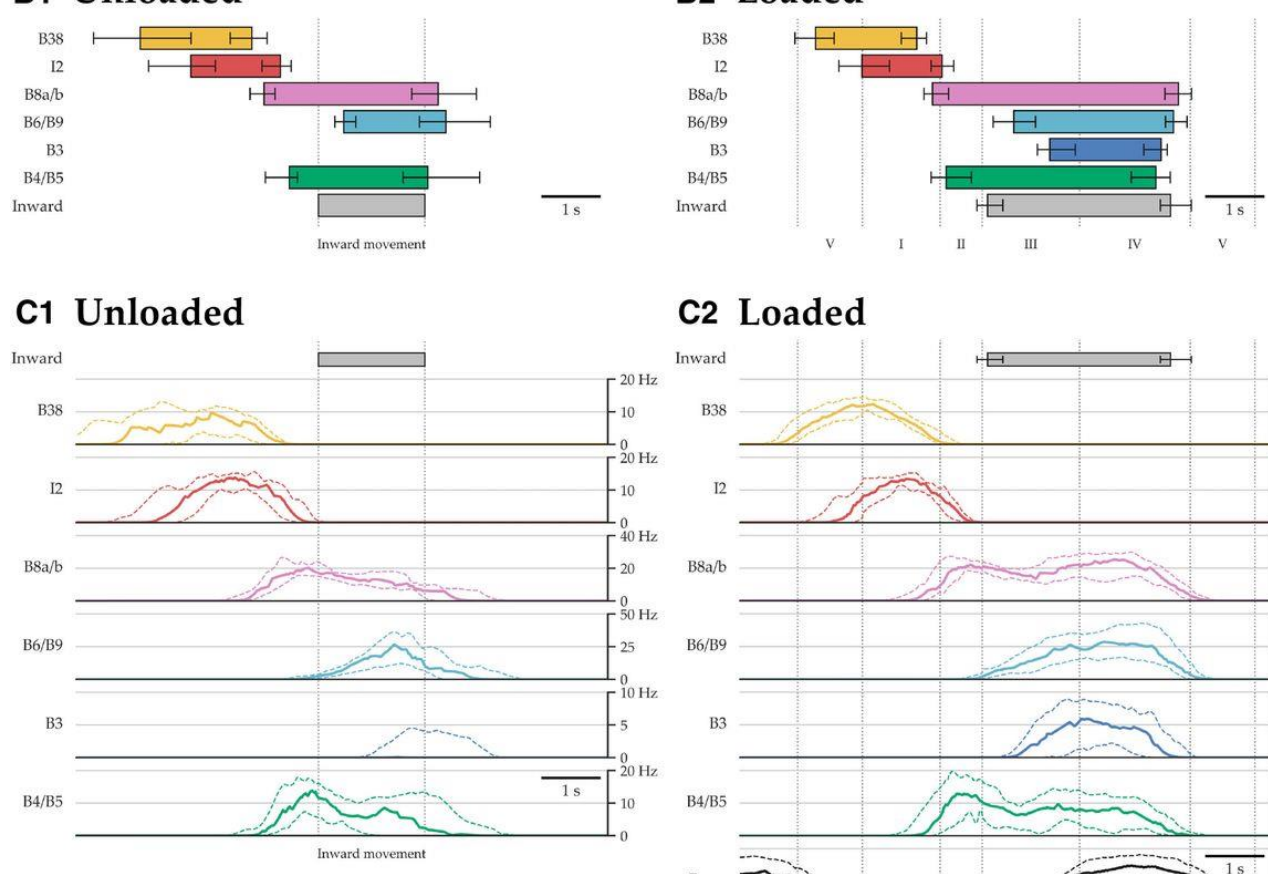

\section{C2 Loaded}

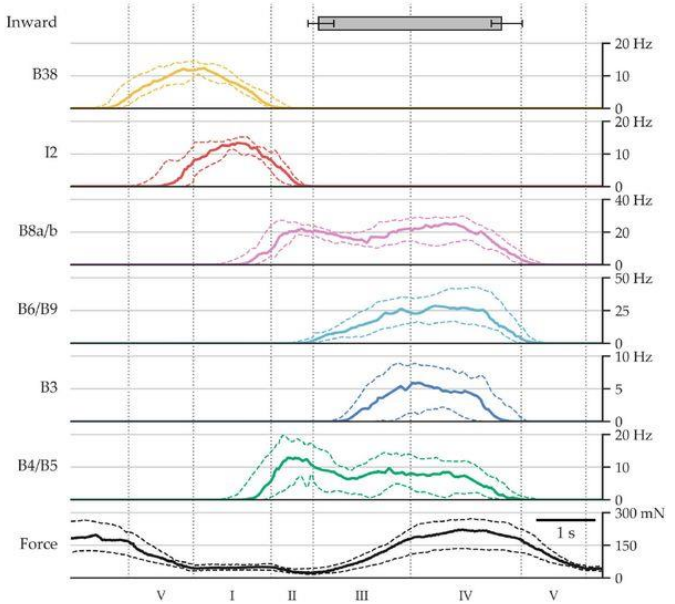

Fig. 5: Aplysia feeding movements vary both within and between different load scenarios.

$\boldsymbol{A}$, The biomechanics and motor control of swallowing. The stages of swallowing a seaweed strip under tension are illustrated schematically in a midsagittal view of the buccal mass, with the anterior opening of the mouth at the right and the esophagus at the left. Closing of the grasper (radula) is illustrated by a change of shape from roughly spherical (stages I, II, and V) to ellipsoidal (stages III and IV). Points of contact between the seaweed and the buccal mass are indicated by black dots. B1-C2, Muscle and identified neuronal activity during unloaded and loaded swallowing. B1, B2, The timing of bursts of identified motor units are plotted for swallows on unloaded seaweed strips (left) and on anchored, unbreakable seaweed strips (right). Boxes indicate median timing, and whiskers indicate the lower and upper quartiles for the beginnings and endings of bursts. The period of seaweed inward movement is similarly indicated. Note the recruitment of B3 bursting into the sequence when the seaweed is under tension (right). $\mathbf{C 1}, \mathbf{C 2}$, The firing frequencies of the units are plotted for the same datasets. Thick lines indicate median frequencies, and dashed lines indicate the lower and upper quartiles for frequency. For loaded swallows (C2), force is similarly plotted, and the drop in force at the end of the previous swallow can be seen at the start (initial stage V). Note that in all traces, the variability in the firing frequencies is large enough for a reversal in sequence between adjacent units. Also here, the recruitment of B3 bursts for loaded seaweed strips is apparent (right). From [126]. 
This sea slug uses its radula, a tongue-like organ, to grasp seaweed and pull it off the substrate and into its mouth (Fig. 5). The animal's vision is poorly developed and the smell or the superficial texture of the seaweed are unreliable predictors of its biomechanical properties, such as toughness or size. The different kinds of seaweeds it feeds on not only vary dramatically in these biomechanical properties before the animals arrive, but they can also change in response to herbivory, or once the animal has started to ingest [126-129]. Therefore, Aplysia has no other choice than trying out how to best ingest the seaweed it is encountering. This process manifests itself not only in a high variability of behavioral parameters between each feeding attempt $[20,130-$ 133], but also during each attempt $[126,134,135]$. Studying the slug nervous system and the biomechanics of the feeding system it controls, it was discovered that Aplysia is searching the state space of its motor system for the behavioral parameters that will get the job done. It does so by not only starting each attempt with a different set of parameters, but also by modifying these parameters online, during the feeding bout, while it is experiencing the responses of the seaweed. In the course of these adjustments, the animal not only varies the timing of when the neurons become active and how strongly, but also recruits 
different different neurons into the sequence if the task requires it (Fig. 5). What to the outside observer appears as two identical behaviors can be two neuronally very different processes. Thus, analogous to the stretch reflexes changing its parameters to probe the responses of the environment, also here, the feeding behavior is highly variable to quickly find suitable behaviors where no pre-arranged sequence can solve the problem. Feeding behavior in Aplysia, when studied on the neuronal level, is also organized in an output/input fashion. This feedback-based organization allows the animal to make moment-to-moment decisions while it is walking through state space to most efficiently find the basin of attraction in state space adequate for the particular food source (i.e., the solution space).

\section{C. elegans olfactory reversal}

With most of the examples studied so far incorporating crucial spontaneous components of endogenous activity (i.e., 'cognition'), it may be useful to select further examples not by behavioral criteria, as the example above, but by neural criteria. As of this writing, the only adult animal with a complete, published connectome is the nematode worm Caenorhabditis elegans (with Drosophila's very close to completion). The connectome of this worm is dominated by connections 
from sensory inputs to motor outputs and less recursive connections than one would expect in, e.g., a mammal. It is straightforward to hypothesize that this architecture would bias the nervous system to a primarily passive-static organization where sensory input is tightly coupled to motor output.

A circuit in the $C$. elegans nervous system that controls reversal behaviors may serve as a particularly instructive example [136,137]. The main component of the system is a neuron called AVA. When AVA is active, the animal reverses its course from forward crawling to backward crawling. Sensory input to this neuron is provided by olfactory neuron AWC. For instance, if AWC is stimulated by an aversive odorant, it becomes depolarized, activates AVA via their synaptic connection and the animal reverses. Conversely, if an attractive odorant hyperpolarizes AWC, AVA does not receive excitatory input, making reversals less likely. Two additional neurons are involved in this circuit, AIB and RIM (Fig. 6). 


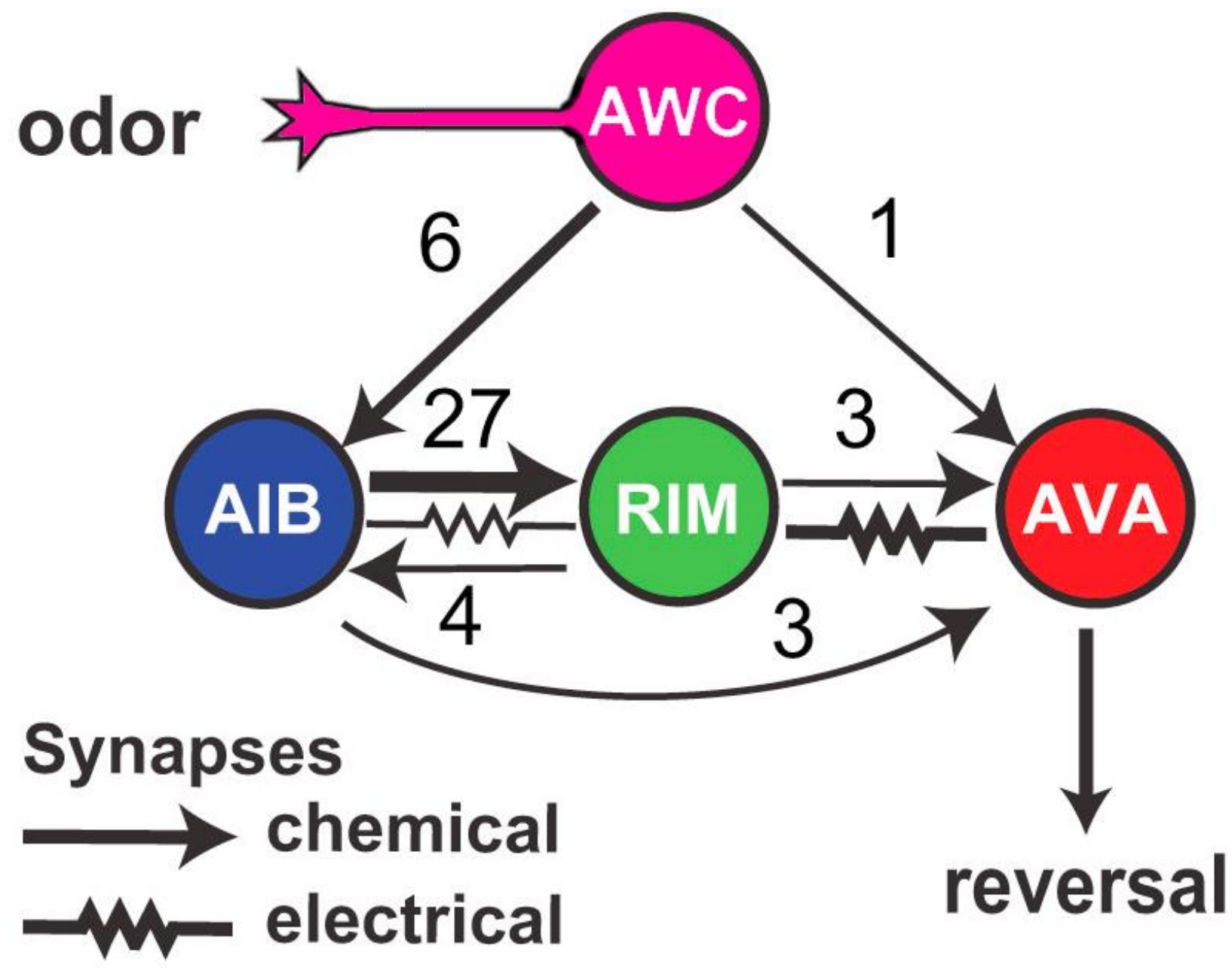

Fig. 6: Olfactory reversal circuit in Caenorhabditis elegans

Sensory neuron AWC expresses receptors for both appetitive and aversive odors. Activity in AWC directly excites both the AVA reversal neuron AVA and interneuron AIB. At the same time, activity in AIB also excites interneuron RIM and AVA. Both interneurons are electrically coupled to each other and to AVA. AIB and RIM are thus reciprocally connected via both chemical and electrical connections. Numbers indicate numbers of synaptic connections (adapted from [136].

Consistent with the overall observation that the $C$. elegans connectome is dominated by connections from sensory input to motor output, also this circuit contains more connections in the 
direction from AWC to AVA, than vice versa. Interestingly, there are also more connections from the AWC sensory neuron to the AIB interneuron than directly to the reversal neuron AVA. If the main purpose of the AWC neuron were to merely tell the AVA neuron whether there is an attractive or aversive odor in the environment, why would it 'relay' this information via interneurons, if a direct connection exists? After all, neurons are the energetically most costly tissue and with only 302 neurons, it does not seem the nematode has any neurons to spare. Especially with regard to a concept of a passive-static nervous system waiting for stimuli to trigger responses, another interesting observation is that this circuit is constantly active, even in the absence of odors in an immobilized animal.

The puzzle of the existence of the two interneurons and their reciprocal connections and their role in the ongoing activity in the absence of stimulation was solved by genetically dissecting the circuit. It was discovered that the role of AIB and RIM was to increase the variability of the reversal circuit. While the input into the circuit from the olfactory neuron AWC always precisely reflected the sensory input, the output of the reversal neuron AVA always varied significantly. This variability was strongly reduced if either AIB or RIM were silenced, or if the reciprocal chemical 
connections were genetically blocked. In other words, removing the interneurons (and in particular their recurrent connections) made the reversal behavior completely dependent on stimulus input, as expected for an input-output system, while the unmodified circuit endowed the animal with a degree of autonomy from sensory inputs. These results make an excellent case for RIM and AIB being incorporated into the reversal circuit specifically to inject variability into an otherwise maladaptively deterministic reversal circuit. Surprisingly, even though the stimulus-response connections dominate the connectivity also here, the variability provided by the feedback connections dominate an adaptive feature of the behavior, its variability. It seems, in such nervous systems, even a disproportionately small feedback component provides a fundamental contribution to the overall architecture. What does this mean for brains whose anatomy appears to be dominated by feedback loops and whose connectivity indicates that it may be more "interested in itself rather than the world outside" [138]?

The example of $C$. elegans reversal also dovetails with the results obtained in Aplysia and the leech: the neurophysiological data from all these systems points towards persistently active nervous systems that constantly perform 'random' walks in their state space in the search for 
feedback. These random walks do not, as if they were purely stochastic, lead to uncoordinated, 'random' behavior but due to attractor states within these systems, decisions between coordinated behaviors are orchestrated in a constant, moment-to-moment interaction with the responses of the environment.

\section{Ancestral input-output systems?}

Given the interneuron-mediated injection of active variability into an otherwise passive input-output C. elegans reversal circuit, perhaps the most ancestral nervous system, one without interneurons, still reflects the default, passive input-output organization? Maybe millions of years of evolution have superimposed cognitive aspects on top of this ancestral state [4], such that extant examples cannot serve as clear demonstrations of the passive sensorimotor organization. Perhaps we need to "ask how a meaningful distinction between cognitive and sensorimotor processes could have emerged, at an empirically definable time in history, within a unified ancestral system for governing adaptive behavior" [38]? Fortunately, there is an animal that fulfills both criteria. The larvae of the marine polychaete Platynereis dumerilii not only serve as a model system for the last common ancestor of all bilaterian 
animals, the Urbilaterian, they also do not have any interneurons. P. dumerilii larvae possess only sensory neurons that make direct contact with the ciliated cells that propel the animal in the water and have therefore been classified as "the simplest sensorimotor system" [139-141].

In the first, dispersal phase of their development, $P$. dumerilii larvae are positively phototactic, while in the later stage, before metamorphosis to the adult worm, they become negatively phototactic. In the early larva, a pair of photoreceptors on each side of the animal mediate positive phototaxis. Because of their monosynaptic connection to the locomotory organs, it is straightforward to hypothesize that the perception of light triggers the phototactic behavior in a dramatically reduced sensorimotor system. However, also here, the connectivity alone is deceiving. The locomotor behavior of the animal is ongoing, even in the absence of any light hitting the photoreceptors. The movements of the larva are non-directional or random without stimuli to guide them, but they are ongoing even without any sensory input. The light activates the photoreceptors which, in turn, inhibit the ciliated cells on the ipsilateral side, such that the animal rotates towards the light by virtue of the ciliated cells contralateral to the light. If anything, this sys- 
tem would be classified as a motor-sensory system, as the behavior clearly is antecedent to the sensory stimulus inhibiting part of the already ongoing motor activity.

These physiological results in an extant model for the Urbilaterian contribute to the hypothesis that early nervous systems evolved to organize a new method of animal motility: muscles. These early nervous systems first evolved to control muscle tissue. Only later were sensory organs connected to the motility organs, likely by feeding back re-afferent sensory input. Passive responses, to the extent that they can even be unequivocally identified, are not primitive, but highly derived traits [32].

\section{Ongoing activity in the absence of input}

The cilia of $P$. dumerilii larvae are beating constantly, propelling the animal through the water even in the absence of any stimuli. Given the position of this model of the Urbilaterian, one may ask whether this ability of generating behavior in the absence of sensory stimulation has been conserved across the bilaterian branch. After all, one prediction of the passive-static concept is that no behavior ought to occur in the absence of stimuli eliciting the behavior. 
In humans, we know from introspection that our brains do not go silent in the absence of stimuli. On the contrary, individuals report that they are starting to hallucinate in sensory deprivation chambers [142]. Research using functional magnetic resonance imaging (fMRI) found that even at rest in the fMRI machine our brains are using nearly the same energy as they are using when focused on a demanding task [25]. These results point to an important role of ongoing activity in the human brain. In line with this insight are close associations between abnormalities in these resting-state networks and many psychiatric disorders [143-149]. However, humans may be unique in this trait and results from humans may not generalize to other animals.

Evidence from animals where explanted nervous systems survive for extended periods shows that even completely deafferented nervous systems are capable of generating coordinated motor programs that correspond to movements in intact animals. Widely known examples are feeding or locomotion in molluscs [150-156], the stomatogastric ganglion of crustaceans $[157,158]$ or locomotion in leeches [159-161]. The observation that a general concept of behavioral control is one of disinhibition, i.e., that appropriate behaviors are selected not by activating them, but by releasing them from tonic inhibition 
$[162,163]$, is also consistent with an active-dynamic concept of nervous system function.

These data suggest a view of nervous systems as constantly active dynamic systems that meander through state space, meta-stably switching between different attractor states while wobbling about, ready to be pushed into other states, e.g., by particularly salient stimuli. Consistent with this interpretation are nonlinear signatures in the temporal structure of turning behavior of tethered fruit flies under sensory deprivation [31], in off-food behavior of C. elegans [30], in isolated leech ganglia or dissociated rat neurons [164].

\section{Ongoing activity interacting with sensory input: the role of behavioral variability}

As the examples of ongoing activity in the absence of sensory input falsify a crucial prediction of the static-passive sensorimotor hypothesis, it is worth briefly revisiting a subset of the examples where sensory stimuli interact with this ongoing activity. In the spinal stretch reflexes, the ongoing descending activity generated the amplitude variations used to find the right amplitude for the current gait. The constant beating of the ciliated cells in the larvae of $P$. dumerlilii allows them to find the light towards which they can 
then swim. In Aplysia, the variability in the feeding behavior enabled them to quickly find the right behavior to bring food into their guts. Thus, while some behavioral variability allows the animal to become unpredictable and hence gain an advantage in a competitive situation, in the just mentioned cases, the animals are using constantly changing behaviors to find solutions to problems: adjust gait, find light, feed.

In all of these examples, the behavioral variability serves the function of trying out in order to find solutions in unpredictable situations. This function of behavioral variability has long been recognized as crucial for a particular set of experiments, operant conditioning [27,37,165174]. In the dynamic-active perspective of brain function, operant conditioning becomes central to understanding the organization of behavior in general: nearly every action will be generated in order to avoid aversive or obtain appetitive feedback. In this context, any exploratory behavior, whether it is concerned directly with sensory feedback or in order to explore a novel environment, is based on actions that are not based on antecedent stimuli. The remaining final function of active behavioral variability is adaptive unpredictability in competitive situations [175-184]. 


\section{Connectomes can be deceiving}

In the three examples of the spinal stretch reflexes, the olfactory reversal connectome of the nematode, or phototaxis in $P$. dumerlii larvae, careful physiological analysis falsified the passive-static hypotheses derived from neural connectivity alone. These three examples also highlight a commonly underestimated more general problem: static neuronal connectivity may deceivingly indicate a passively organized system (Fig. $1 \mathrm{~b})$ to the superficial observer, while only careful dissection of the function and physiology of the circuit can reveal the active-dynamic system (Fig. 1c) it actually implements. It becomes more and more apparent that even if there were anatomical features from the connectome projects in more complex organisms prompting such a hypothesis, proposing a passive-static organization on the basis of connectomic data alone would be reckless. Without the dynamics of the system, the static connectivity tells us nothing. Conversely, we cannot understand the functional dynamics of nervous systems, without knowing their anatomical connectivity. The connectome is a necessary, but not even close to a sufficient condition for understanding the functional organization of any nervous system. 
Another reason why connectomes may be deceiving is not only because of active neuronal dynamics, but also due to neuromodulation rendering the connectivity itself highly dynamic [32]. For instance, naive Aplysia slugs show weak connectivity between three feeding-initiating neurons as well as a high burst threshold and low input resistance in a decision-making neuron $[20,133,185]$. After receiving contingent food reward, the connectivity between the behavior-initiating neurons is increased, increasing the frequency of feeding behaviors. The decision-making neuron increases its input resistance and lowers its burst threshold making it much more likely to fire and thus being recruited into any feeding behavior. The connectivity changes thus bias any future feeding behaviors towards those that were effective in bringing food into the gut of the animal. These data suggest that the connectivity of the feeding system before the reward is more flexible to explore its state space than after the rewarding experience, when the tightened connectivity between the specific neurons that were active during or immediately preceding the reward, biases the system to visit the rewarded areas of the state space more frequently. The molecular and cellular processes by which neuromodulation dynamically adjusts not only the ex- 
citability of neurons, but also their synaptic dynamics, action potential propagation or even their survival is well-documented [186-189]. The neuromodulatory system itself is often not organized according to the synaptic connectivity between neurons, but paracrine secretion of neuromodulators constitutes a non-anatomical, chemical network such that the synaptic connectome represents only one of many layers [190].

\section{Do passive nervous systems exist?}

The examples described above suggest that the passive-static stimulus-response concept so dominant in neuroscience may be based largely on an overgeneralization of laboratory artifacts. The superficial appearance of a stimulusresponse organization emerges when either highly specialized, rare behaviors (such as predictable escape responses) are studied or when experimental conditions or preparations are designed such that intrinsic activity is minimized. However, while the falsifying examples described here strongly suggest that the organisms studied in neuroscience evolved active-dynamic nervous systems in order to exert control over their movements and, hence, their environment, they do not exclude that other organisms may have evolved a passive nervous system. All animals mentioned 
above are foraging animals. Sit and wait, ambush predators spring to mind as potential counter-examples. These animals may face significant selection pressures to conserve energy and reduce neural activity as much as possible. Some of these predators can survive for relatively long periods of time without a meal. Perhaps they accomplish this feat by reducing the activity of their most energetically costly tissue, neurons?

Thus, despite all the evidence supporting the concept of active brains, genuine responses may exist within a passive nervous system somewhere in the animal kingdom, but so far, there is little evidence for them. Research into animals other than the foraging animals typically studied in neuroscience may be required to discover behaviors that can be classified as genuine responses.

\section{References:}

[1] O. Güntürkün, Onur Güntürkün, Curr. Biol. 25 (2015) R970-R971.

[2] D. Poeppel, F. Adolfi, Against the Epistemological Primacy of the Hardware: The Brain from Inside Out, Turned Upside Down, eNeuro. 7 (2020). https://doi.org/10.1523/ENEURO.0215-20.2020.

[3] Y. Niv, The primacy of behavioral research for understanding the brain, PsyArXiv. (2020).

[4] P. Cisek, J.F. Kalaska, Neural mechanisms for interacting with a world full of action choices, Annu. Rev. Neurosci. 33 (2010) 269-298.

[5] W. James, The principles of psychology, Vol I, (1890). https://doi.org/10.1037/10538-000.

[6] C. Sotelo, Viewing the brain through the master hand of Ramón y Cajal, Nat. Rev. Neurosci. 4 (2003) 71-77.

[7] C.S. Sherrington, Flexion-reflex of the limb, crossed extension-reflex, and reflex stepping and standing, J. Physiol. 40 (1910) 28-121.

[8] V.M. Bekhterev, General principles of human reflexology, Ayer Co Pub, 1932.

[9] D.O. Hebb, The Organization of Behavior, John Wiley \& Sons, 1949.

[10] A. Dickinson, Actions and habits: the development of behavioural autonomy, Philos. Trans. R. Soc. Lond. B Biol. Sci. 308 (1985) 67-78.

[11] M.D. Mauk, The potential effectiveness of simulations versus phenomenological models, Nat. Neurosci. 3 (2000) 649-651.

[12] A. Pouget, L.H. Snyder, Computational approaches to sensorimotor transformations, Nat. Neurosci. 3 Suppl (2000) 11921198. 
[13] A. Abbott, Inside the mind of an animal, Nature. 584 (2020) 182-185.

[14] A. Masuzzo, M. Montanari, L. Kurz, J. Royet, How Bacteria Impact Host Nervous System and Behaviors: Lessons from Flies and Worms, Trends Neurosci. (2020). https://doi.org/10.1016/j.tins.2020.09.007.

[15] T. Graham-Brown, On the nature of the fundamental activity of the nervous centres; together with an analysis of the conditioning of rhythmic activity in progression, and a theory of the evolution of function in the nervous system, J. Physiol. 48 (1914) 18-46.

[16] R. Lydic, Central pattern-generating neurons and the search for general principles, FASEB J. 3 (1989) $2457-2468$.

[17] H. Berger, Über das Elektrenkephalogramm des Menschen, Archiv F. Psychiatrie. 87 (1929) 527-570.

[18] B.O. Alving, Spontaneous activity in isolated somata of Aplysia pacemaker neurons, J. Gen. Physiol. 51 (1968) $29-45$.

[19] T. Elbert, W.J. Ray, Z.J. Kowalik, J.E. Skinner, K.E. Graf, N. Birbaumer, Chaos and physiology: deterministic chaos in excitable cell assemblies, Physiol. Rev. 74 (1994) 1-47.

[20] R. Nargeot, J. Simmers, Functional organization and adaptability of a decision-making network in aplysia, Front. Neurosci. $6(2012) 113$.

[21] W.T. Powers, R.K. Clark, R.L.M. Farland, A General Feedback Theory of Human Behavior: Part I, Percept. Mot. Skills. 11 (1960) 71-88.

[22] W.H. Calvin, The Cerebral Symphony: Seashore Reflections on the Structure of Consciousness, Backinprint.Com, 2000.

[23] P. Cisek, Beyond the computer metaphor: behaviour as interaction, Journal of Consciousness Studies. 6 (1999) $125-142$.

[24] R. Yuste, J.N. MacLean, J. Smith, A. Lansner, The cortex as a central pattern generator, Nat. Rev. Neurosci. 6 (2005) 477483.

[25] M.E. Raichle, Two views of brain function, Trends Cogn. Sci. 14 (2010) 180-190.

[26] Z.W. Davis, L. Muller, J. Martinez-Trujillo, T. Sejnowski, J.H. Reynolds, Spontaneous travelling cortical waves gate perception in behaving primates, Nature. 58 (2020) 181.

[27] M. Heisenberg, The beauty of the network in the brain and the origin of the mind in the control of behavior, J. Neurogenet. 28 (2014) 389-399.

[28] G. Northoff, S. Wainio-Theberge, K. Evers, Spatiotemporal neuroscience - what is it and why we need it, Phys. Life Rev. 33 (2020) 78-87.

[29] L.L. Thurstone, The Stimulus-Response Fallacy in Psychology, Psychol. Rev. 30 (1923) 354-369.

[30] T. Ahamed, A.C. Costa, G.J. Stephens, Capturing the continuous complexity of behaviour in Caenorhabditis elegans, Nat. Phys. (2020) 1-9.

[31] A. Maye, C.-H. Hsieh, G. Sugihara, B. Brembs, Order in Spontaneous Behavior, SciVee. (2007). https://doi.org/10.4016/726.01.

[32] F. Keijzer, M. van Duijn, P. Lyon, What nervous systems do: early evolution, input-output, and the skin brain thesis, Adapt. Behav. 21 (2013) 67-85.

[33] B. Brembs, W. Plendl, Double dissociation of PKC and AC manipulations on operant and classical learning in Drosophila, Curr. Biol. 18 (2008) 1168-1171.

[34] M. Brown, How I Killed Pluto and Why It Had It Coming, Spiegel \& Grau Trade Paperbacks, 2012.

[35] C. Bernard, Calling Names, eNeuro. 7 (2020). https://doi.org/10.1523/ENEURO.0314-20.2020.

[36] H. Yin, The crisis in neuroscience, in: The Interdisciplinary Handbook of Perceptual Control Theory, Elsevier, 2020: pp. 2348.

[37] H.C. Bell, Behavioral Variability in the Service of Constancy, Int. J. Comp. Psychol. 27 (2014). https://escholarship.org/content/qt0ch4g2x6/qt0ch4g2x6.pdf?t=nfi64p (accessed October 7, 2020).

[38] P. Cisek, Resynthesizing behavior through phylogenetic refinement, Atten. Percept. Psychophys. 81 (2019) $2265-2287$.

[39] F. Keijzer, Demarcating cognition: the cognitive life sciences, Synthese. (2020) 1-21.

[40] T. Bayne, D. Brainard, R.W. Byrne, L. Chittka, N. Clayton, C. Heyes, J. Mather, B. Ölveczky, M. Shadlen, T. Suddendorf, B. Webb, What is cognition?, Curr. Biol. 29 (2019) R608-R615.

[41] T.H. Leahey, A history of psychology: main currents in psychological thought, Prentice Hall, 1987.

[42] J. Virués-Ortega, The Case Against B. F. Skinner 45 years Later: An Encounter with N. Chomsky, Behav. Anal. 29 (2006) 243251.

[43] N. Smith, Chomsky: Ideas and Ideals, Cambridge University Press, 1999.

[44] J.P. Watrin, R. Darwich, On Behaviorism in the Cognitive Revolution: Myth and Reactions, Rev. Gen. Psychol. 16 (2012) 269282.

[45] D.C. Palmer, On Chomsky's Appraisal of Skinner's Verbal Behavior: A Half Century of Misunderstanding, Behav. Anal. 29 (2006) 253-267.

[46] R.M. Harnish, D.D. Cummins, Minds, Brains, and Computers: An Historical Introduction to the Foundations of Cognitive Science, Wiley-Blackwell, 2000.

[47] E. Bialystock, Anatomy of a revolution, in: David Marter Johnson Christina (Ed.), The Future of the Cognitive Revolution, New York: Oxford University Press, 1997: pp. 109-113.

[48] B.E. Adelman, An underdiscussed aspect of chomsky (1959), Anal. Verbal Behav. 23 (2007) 29-34.

[49] U. Neisser, Cognitive Psychology: Classic Edition, Psychology Press, 1967. 
[50] G. Buzsáki, A. Peyrache, J. Kubie, Emergence of Cognition from Action, Cold Spring Harb. Symp. Quant. Biol. 79 (2014) 41 50.

[51] F.C. Fulda, Natural Agency: The Case of Bacterial Cognition, Journal of the American Philosophical Association. 3 (2017) 69-90. https://doi.org/10.1017/apa.2017.5.

[52] J.R. Wolpaw, The complex structure of a simple memory, Trends Neurosci. 20 (1997) 588-594.

[53] A.K. Thompson, J.R. Wolpaw, The simplest motor skill: mechanisms and applications of reflex operant conditioning, Exerc. Sport Sci. Rev. 42 (2014) 82-90.

[54] A.K. Thompson, J.R. Wolpaw, Operant conditioning of spinal reflexes: from basic science to clinical therapy, Front. Integr. Neurosci. 8 (2014) 25.

[55] A.K. Thompson, J.R. Wolpaw, H-reflex conditioning during locomotion in people with spinal cord injury, J. Physiol. (2019). https://doi.org/10.1113/JP278173.

[56] Y. Chen, L. Chen, Y. Wang, X.Y. Chen, J.R. Wolpaw, Why New Spinal Cord Plasticity Does Not Disrupt Old Motor Behaviors, J. Neurosci. 37 (2017) 8198-8206.

[57] X.Y. Chen, Y. Wang, Y. Chen, L. Chen, J.R. Wolpaw, The inferior olive is essential for long-term maintenance of a simple motor skill, J. Neurophysiol. 116 (2016) 1946-1955.

[58] J.R. Wolpaw, Operant conditioning of primate spinal reflexes: the H-reflex, J. Neurophysiol. 57 (1987) $443-459$.

[59] J.R. Wolpaw, C.L. Lee, Memory traces in primate spinal cord produced by operant conditioning of H-reflex, J. Neurophysiol. 61 (1989) 563-572.

[60] J.R. Wolpaw, P.A. Herchenroder, Operant conditioning of H-reflex in freely moving monkeys, J. Neurosci. Methods. 31 (1990) 145-152.

[61] J.S. Carp, J.R. Wolpaw, Motoneuron plasticity underlying operantly conditioned decrease in primate H-reflex, J. Neurophysiol. 72 (1994) 431-442.

[62] X.Y. Chen, J.R. Wolpaw, Operant conditioning of H-reflex in freely moving rats, J. Neurophysiol. 73 (1995) $411-415$.

[63] J.A. Halter, J.S. Carp, J.R. Wolpaw, Operantly conditioned motoneuron plasticity: possible role of sodium channels, J. Neurophysiol. 73 (1995) 867-871.

[64] K.C. Feng-Chen, J.R. Wolpaw, Operant conditioning of H-reflex changes synaptic terminals on primate motoneurons, Proc. Natl. Acad. Sci. U. S. A. 93 (1996) 9206-9211.

[65] J.S. Carp, X.Y. Chen, H. Sheikh, J.R. Wolpaw, Operant conditioning of rat H-reflex affects motoneuron axonal conduction velocity, Exp. Brain Res. 136 (2001) 269-273.

[66] X.Y. Chen, L. Chen, J.R. Wolpaw, Time course of H-reflex conditioning in the rat, Neurosci. Lett. 302 (2001) 85-88.

[67] J.S. Carp, X.Y. Chen, H. Sheikh, J.R. Wolpaw, Motor unit properties after operant conditioning of rat H-reflex, Exp. Brain Res. 140 (2001) 382-386.

[68] X.Y. Chen, J.S. Carp, L. Chen, J.R. Wolpaw, Corticospinal tract transection prevents operantly conditioned H-reflex increase in rats, Exp. Brain Res. 144 (2002) 88-94.

[69] Y. Wang, S. Pillai, J.R. Wolpaw, X.Y. Chen, Motor learning changes GABAergic terminals on spinal motoneurons in normal rats, Eur. J. Neurosci. 23 (2006) 141-150.

[70] J.R. Wolpaw, The cerebellum in maintenance of a motor skill: A hierarchy of brain and spinal cord plasticity underlies $\mathrm{H}$ reflex conditioning, Learn. Mem. 13 (2006) 208-215.

[71] X.Y. Chen, J.S. Carp, L. Chen, J.R. Wolpaw, Sensorimotor cortex ablation prevents H-reflex up-conditioning and causes a paradoxical response to down-conditioning in rats, J. Neurophysiol. 96 (2006) 119-127.

[72] J.S. Carp, A.M. Tennissen, X.Y. Chen, J.R. Wolpaw, H-reflex operant conditioning in mice, J. Neurophysiol. 96 (2006) 17181727.

[73] Y. Chen, X.Y. Chen, L.B. Jakeman, L. Chen, B.T. Stokes, J.R. Wolpaw, Operant conditioning of H-reflex can correct a locomotor abnormality after spinal cord injury in rats, J. Neurosci. 26 (2006) 12537-12543.

[74] Y. Chen, L. Chen, Y. Wang, J.R. Wolpaw, X.Y. Chen, Operant conditioning of rat soleus H-reflex oppositely affects another H-reflex and changes locomotor kinematics, J. Neurosci. 31 (2011) 11370-11375.

[75] X.Y. Chen, Y. Wang, Y. Chen, L. Chen, J.R. Wolpaw, Ablation of the inferior olive prevents H-reflex down-conditioning in rats, J. Neurophysiol. 115 (2016) 1630-1636.

[76] R.A. Davidoff, Skeletal muscle tone and the misunderstood stretch reflex, Neurology. 42 (1992) 951-963.

[77] R.S. McEwen, The reactions to light and to gravity in Drosophila and its mutants, Journal of Experimental Zoology. 25 (1918) 49-106. https://doi.org/10.1002/jez.1400250103.

[78] E.A. Gorostiza, J. Colomb, B. Brembs, A decision underlies phototaxis in an insect, Open Biol. 6 (2016). https://doi.org/10.1098/rsob.160229.

[79] M. Heisenberg, The Beauty of the Network in the Brain and the Origin of the Mind in the Control of Behavior, Journal of Neurogenetics. 28 (2014) 389-399. https://doi.org/10.3109/01677063.2014.912279.

[80] I.M.S. Steymans, Behavioral Variability in phototaxis of Drosophila melanogaster, Bachelor of Science, Universität Regensburg, 2016. http://lab.brembs.net/wp/wp-content/uploads/theses/steymans_bachelor.pdf (accessed October 2, 2020).

[81] R.C. Eaton, R. DiDomenico, J. Nissanov, Flexible body dynamics of the goldfish C-start: implications for reticulospinal command mechanisms, J. Neurosci. 8 (1988) 2758-2768. 
[82] J.R. Fetcho, D.S. Faber, Identification of motoneurons and interneurons in the spinal network for escapes initiated by the mauthner cell in goldfish, J. Neurosci. 8 (1988) 4192-4213.

[83] J. Nissanov, R.C. Eaton, R. DiDomenico, The motor output of the Mauthner cell, a reticulospinal command neuron, Brain Res. 517 (1990) 88-98.

[84] R.C. Eaton, R. DiDomenico, J. Nissanov, Role of the Mauthner cell in sensorimotor integration by the brain stem escape network, Brain Behav. Evol. 37 (1991) 272-285.

[85] R.C. Eaton, R.K.K. Lee, M.B. Foreman, The Mauthner cell and other identified neurons of the brainstem escape network of fish, Prog. Neurobiol. 63 (2001) 467-485.

[86] H.S. Bierman, J.E. Schriefer, S.J. Zottoli, M.E. Hale, The effects of head and tail stimulation on the withdrawal startle response of the rope fish (Erpetoichthys calabaricus), J. Exp. Biol. 207 (2004) 3985-3997.

[87] T. Preuss, P.E. Osei-Bonsu, S.A. Weiss, C. Wang, D.S. Faber, Neural representation of object approach in a decision-making motor circuit, J. Neurosci. 26 (2006) 3454-3464.

[88] S.A. Weiss, S.J. Zottoli, S.C. Do, D.S. Faber, T. Preuss, Correlation of C-start behaviors with neural activity recorded from the hindbrain in free-swimming goldfish (Carassius auratus), J. Exp. Biol. 209 (2006) 4788-4801.

[89] J.G. Canfield, Some voluntary C-bends may be Mauthner neuron initiated, J. Comp. Physiol. A Neuroethol. Sens. Neural Behav. Physiol. 193 (2007) 1055-1064.

[90] M. Takahashi, M. Inoue, M. Tanimoto, T. Kohashi, Y. Oda, Short-term desensitization of fast escape behavior associated with suppression of Mauthner cell activity in larval zebrafish, Neurosci. Res. 121 (2017) 29-36.

[91] B. Roy, D.W. Ali, Patch clamp recordings from embryonic zebrafish Mauthner cells, J. Vis. Exp. (2013). https://doi.org/10.3791/50551.

[92] D. Bodian, The structure of the vertebrate synapse. A study of the axon endings on mauthner's cell and neighboring centers in the goldfish, J. Comp. Neurol. 68 (1937) 117-159.

[93] M.E. Hale, H.R. Katz, M.Y. Peek, R.T. Fremont, Neural circuits that drive startle behavior, with a focus on the Mauthner cells and spiral fiber neurons of fishes, J. Neurogenet. 30 (2016) 89-100.

[94] T. Shimazaki, M. Tanimoto, Y. Oda, S.-I. Higashijima, Behavioral Role of the Reciprocal Inhibition between a Pair of Mauthner Cells during Fast Escapes in Zebrafish, J. Neurosci. 39 (2019) 1182-1194.

[95] S.J. Zottoli, Correlation of the startle reflex and Mauthner cell auditory responses in unrestrained goldfish, J. Exp. Biol. 66 (1977) 243-254.

[96] R.C. Eaton, W.A. Lavender, C.M. Wieland, Identification of Mauthner-initiated response patterns in goldfish: Evidence from simultaneous cinematography and electrophysiology, J. Comp. Physiol. 144 (1981) 521-531.

[97] K.C. Catania, Born knowing: tentacled snakes innately predict future prey behavior, PLoS One. 5 (2010) e10953.

[98] K.C. Catania, The brain and behavior of the tentacled snake, Ann. N. Y. Acad. Sci. 1225 (2011) 83-89.

[99] K.C. Catania, Tentacled snakes turn C-starts to their advantage and predict future prey behavior, Proc. Natl. Acad. Sci. U. S. A. 106 (2009) 11183-11187.

[100] H. Augustin, A. Zylbertal, L. Partridge, A Computational Model of the Escape Response Latency in the Giant Fiber System of, eNeuro. 6 (2019). https://doi.org/10.1523/ENEURO.0423-18.2019.

[101] J.M. Ache, J. Polsky, S. Alghailani, R. Parekh, P. Breads, M.Y. Peek, D.D. Bock, C.R. von Reyn, G.M. Card, Neural Basis for Looming Size and Velocity Encoding in the Drosophila Giant Fiber Escape Pathway, Curr. Biol. 29 (2019) 1073-1081.e4.

[102] S.E.J. de Vries, T. Clandinin, Optogenetic stimulation of escape behavior in Drosophila melanogaster, J. Vis. Exp. (2013). https://doi.org/10.3791/50192.

[103] M. Mejia, M.D. Heghinian, A. Busch, C.J. Armishaw, F. Marí, T.A. Godenschwege, A novel approach for in vivo screening of toxins using the Drosophila Giant Fiber circuit, Toxicon. 56 (2010) 1398-1407.

[104] M.J. Allen, T.A. Godenschwege, Electrophysiological recordings from the Drosophila giant fiber system (GFS), Cold Spring Harb. Protoc. 2010 (2010) db.prot5453.

[105] J.E. Engel, C.-F. Wu, Neurogenetic approaches to habituation and dishabituation in Drosophila, Neurobiol. Learn. Mem. 92 (2009) 166-175.

[106] S. Hammond, M. O'Shea, Escape flight initiation in the fly, J. Comp. Physiol. A Neuroethol. Sens. Neural Behav. Physiol. 193 (2007) 471-476.

[107] J.E. Engel, C.F. Wu, Interactions of membrane excitability mutations affecting potassium and sodium currents in the flight and giant fiber escape systems of Drosophila, J. Comp. Physiol. A. 171 (1992) 93-104.

[108] R.J. Wyman, J.B. Thomas, L. Salkoff, D.G. King, The Drosophila Giant Fiber System, in: R.C. Eaton (Ed.), Neural Mechanisms of Startle Behavior, Springer US, Boston, MA, 1984: pp. 133-161.

[109] M.R. Hummon, W.J. Costello, Giant fiber activation of flight muscles in Drosophila: asynchrony in latency of wing depressor fibers, J. Neurobiol. 20 (1989) 593-602.

[110] M. Koto, M.A. Tanouye, A. Ferrus, J.B. Thomas, R.J. Wyman, The morphology of the cervical giant fiber neuron ofDrosophila, Brain Res. 221 (1981) 213-217.

[111] M.E. Power, The thoracico-abdominal nervous system of an adult insect, Drosophila melanogaster, J. Comp. Neurol. 88 (1948) 347-409. 
[112] P.G. Jabloński, N.J. Strausfeld, Exploitation of an ancient escape circuit by an avian predator: prey sensitivity to model predator display in the field, Brain Behav. Evol. 56 (2000) 94-106.

[113] P.G. Jabłoński, N.J. Strausfeld, Exploitation of an ancient escape circuit by an avian predator: relationships between taxonspecific prey escape circuits and the sensitivity to visual cues from the predator, Brain Behav. Evol. 58 (2001) 218-240.

[114] K.C. Catania, Worm grunting, fiddling, and charming--humans unknowingly mimic a predator to harvest bait, PLoS One. 3 (2008) e3472.

[115] O. Mitra, M.A. Callaham Jr, M.L. Smith, J.E. Yack, Grunting for worms: seismic vibrations cause Diplocardia earthworms to emerge from the soil, Biol. Lett. 5 (2009) 16-19.

[116] A. Royan, A.P. Muir, J.R. Downie, Variability in escape trajectory in the Trinidadian stream frog and two treefrogs at different life-history stages, Can. J. Zool. 88 (2010) 922-934.

[117] C. Comer, Behavioral biology: inside the mind of proteus?, Curr. Biol. 19 (2009) R27-8.

[118] P. Domenici, D. Booth, J.M. Blagburn, J.P. Bacon, Cockroaches keep predators guessing by using preferred escape trajectories, Curr. Biol. 18 (2008) 1792-1796.

[119] P. Domenici, D. Booth, J.M. Blagburn, J.P. Bacon, Escaping away from and towards a threat: the cockroach's strategy for staying alive, Commun. Integr. Biol. 2 (2009) 497-500.

[120] T.Y. Moore, K.L. Cooper, A.A. Biewener, R. Vasudevan, Unpredictability of escape trajectory explains predator evasion ability and microhabitat preference of desert rodents, Nat. Commun. 8 (2017) 440.

[121] S. Edut, D. Eilam, Protean behavior under barn-owl attack: voles alternate between freezing and fleeing and spiny mice flee in alternating patterns, Behav. Brain Res. 155 (2004) 207-216.

[122] J. Herberholz, G.D. Marquart, Decision Making and Behavioral Choice during Predator Avoidance, Front. Neurosci. 6 (2012) 125.

[123] D.A. Evans, A.V. Stempel, R. Vale, T. Branco, Cognitive Control of Escape Behaviour, Trends Cogn. Sci. 23 (2019) $334-348$.

[124] K.L. Briggman, H.D.I. Abarbanel, W.B. Kristan Jr, Optical imaging of neuronal populations during decision-making, Science. 307 (2005) 896-901.

[125] W.B. Kristan, Neuronal decision-making circuits, Curr. Biol. 18 (2008) R928-32.

[126] J.P. Gill, H.J. Chiel, Rapid Adaptation to Changing Mechanical Load by Ordered Recruitment of Identified Motor Neurons, eNeuro. 7 (2020). https://doi.org/10.1523/ENEURO.0016-20.2020.

[127] I. Hurwitz, A.J. Susswein, Adaptation of Feeding Sequences in Aplysia Oculifera to Changes in the Load and Width of Food, J. Exp. Biol. 166 (1992) 215-235.

[128] A.J. Susswein, M. Schwarz, E. Feldman, Learned changes of feeding behavior in Aplysia in response to edible and inedible foods, J. Neurosci. 6 (1986) 1513-1527.

[129] N.P. Burnett, M.A.R. Koehl, Mechanical properties of the wave-swept kelp Egregia menziesii change with season, growth rate and herbivore wounds, J. Exp. Biol. 222 (2019). https://doi.org/10.1242/jeb.190595.

[130] V. Brezina, A. Proekt, K.R. Weiss, Cycle-to-cycle variability as an optimal behavioral strategy, Neurocomputing. 69 (2006) $1120-1124$.

[131] C.S. Lum, Y. Zhurov, E.C. Cropper, K.R. Weiss, V. Brezina, Variability of swallowing performance in intact, freely feeding aplysia, J. Neurophysiol. 94 (2005) 2427-2446.

[132] C.C. Horn, Y. Zhurov, I.V. Orekhova, A. Proekt, I. Kupfermann, K.R. Weiss, V. Brezina, Cycle-to-cycle variability of neuromuscular activity in Aplysia feeding behavior, J. Neurophysiol. 92 (2004) 157-180.

[133] R. Nargeot, M. Le Bon-Jego, J. Simmers, Cellular and network mechanisms of operant learning-induced compulsive behavior in Aplysia, Curr. Biol. 19 (2009) 975-984.

[134] M.J. Cullins, J.P. Gill, J.M. McManus, H. Lu, K.M. Shaw, H.J. Chiel, Sensory Feedback Reduces Individuality by Increasing Variability within Subjects, Curr. Biol. 25 (2015) 2672-2676.

[135] M.J. Cullins, K.M. Shaw, J.P. Gill, H.J. Chiel, Motor neuronal activity varies least among individuals when it matters most for behavior, J. Neurophysiol. 113 (2015) 981-1000.

[136] A. Gordus, N. Pokala, S. Levy, S.W. Flavell, C.I. Bargmann, Feedback from network states generates variability in a probabilistic olfactory circuit, Cell. 161 (2015) 215-227.

[137] W.B. Kristan, Pinning down randomness, Cell. 161 (2015) 189-190.

[138] G. Buzsáki, The Brain-Cognitive Behavior Problem: A Retrospective, eNeuro. 7 (2020). https://doi.org/10.1523/ENEURO.0069-20.2020.

[139] G. Jékely, J. Colombelli, H. Hausen, K. Guy, E. Stelzer, F. Nédélec, D. Arendt, Mechanism of phototaxis in marine zooplankton, Nature. 456 (2008) 395-399.

[140] N. Randel, G. Jékely, Phototaxis and the origin of visual eyes, Philos. Trans. R. Soc. Lond. B Biol. Sci. 371 (2016) 20150042.

[141] D. Arendt, K. Tessmar, M.-I.M. de Campos-Baptista, A. Dorresteijn, J. Wittbrodt, Development of pigment-cup eyes in the polychaete Platynereis dumerilii and evolutionary conservation of larval eyes in Bilateria, Development. 129 (2002) 11431154.

[142] M. Raz, Alone again: John Zubek and the troubled history of sensory deprivation research, J. Hist. Behav. Sci. 49 (2013) 379-395. 
[143] S.M. Soman, S. Raghavan, P.G. Rajesh, N. Mohanan, B. Thomas, C. Kesavadas, R.N. Menon, Does resting state functional connectivity differ between mild cognitive impairment and early Alzheimer's dementia?, J. Neurol. Sci. 418 (2020) 117093.

[144] B. Conio, M. Martino, P. Magioncalda, A. Escelsior, M. Inglese, M. Amore, G. Northoff, Opposite effects of dopamine and serotonin on resting-state networks: review and implications for psychiatric disorders, Mol. Psychiatry. 25 (2020) 82-93.

[145] H. Zhang, Y. Zhao, W. Cao, D. Cui, Q. Jiao, W. Lu, H. Li, J. Qiu, Aberrant functional connectivity in resting state networks of ADHD patients revealed by independent component analysis, BMC Neurosci. 21 (2020) 39.

[146] R.L. Buckner, J.R. Andrews-Hanna, D.L. Schacter, The Brain's Default Network: Anatomy, Function, and Relevance to Disease, Ann. N. Y. Acad. Sci. 1124 (2008) 1-38.

[147] M.D. Cohn, L.E. Pape, L. Schmaal, W. van den Brink, G. van Wingen, R.R.J.M. Vermeiren, T.A.H. Doreleijers, D.J. Veltman, A. Popma, Differential relations between juvenile psychopathic traits and resting state network connectivity, Hum. Brain Mapp. 36 (2015) 2396-2405.

[148] M. Cataldi, M. Avoli, E. de Villers-Sidani, Resting state networks in temporal lobe epilepsy, Epilepsia. 54 (2013) $2048-2059$.

[149] H. Karbasforoushan, N.D. Woodward, Resting-state networks in schizophrenia, Curr. Top. Med. Chem. 12 (2012) $2404-$ 2414.

[150] R.M. Rose, Burst activity of the buccal ganglion of Aplysia depilans, J. Exp. Biol. 56 (1972) 735-754.

[151] A.J. Susswein, J.H. Byrne, Identification and characterization of neurons initiating patterned neural activity in the buccal ganglia of Aplysia, J. Neurosci. 8 (1988) 2049-2061.

[152] W.S. Sossin, M.D. Kirk, R.H. Scheller, Peptidergic modulation of neuronal circuitry controlling feeding in Aplysia, J. Neurosci. 7 (1987) 671-681.

[153] E.A. Kabotyanski, D.A. Baxter, S.J. Cushman, J.H. Byrne, Modulation of fictive feeding by dopamine and serotonin in aplysia, J. Neurophysiol. 83 (2000) 374-392.

[154] R. Nargeot, D.A. Baxter, J.H. Byrne, Contingent-Dependent Enhancement of Rhythmic Motor Patterns: An In Vitro Analog of Operant Conditioning, J. Neurosci. 17 (1997) 8093-8105.

[155] W.H. Watson 3rd, J.M. Newcomb, S. Thompson, Neural correlates of swimming behavior in Melibe leonina, Biol. Bull. 203 (2002) 152-160.

[156] E.M. Quinlan, B.C. Arnett, A.D. Murphy, Feeding stimulants activate an identified dopaminergic interneuron that induces the feeding motor program in Helisoma, J. Neurophysiol. 78 (1997) 812-824.

[157] D. Combes, P. Meyrand, J. Simmers, Motor Pattern Specification by Dual Descending Pathways to a Lobster Rhythm-Generating Network, J. Neurosci. 19 (1999) 3610-3619.

[158] D. Combes, P. Meyrand, J. Simmers, Dynamic Restructuring of a Rhythmic Motor Program by a Single Mechanoreceptor Neuron in Lobster, J. Neurosci. 19 (1999) 3620-3628.

[159] M.S. Thorogood, P.D. Brodfuehrer, The role of glutamate in swim initiation in the medicinal leech, Invert. Neurosci. 1 (1995) 223-233.

[160] J.G. Puhl, K.A. Mesce, Dopamine activates the motor pattern for crawling in the medicinal leech, J. Neurosci. 28 (2008) 4192-4200.

[161] K.L. Briggman, W.B. Kristan Jr, Imaging dedicated and multifunctional neural circuits generating distinct behaviors, J. Neurosci. 26 (2006) 10925-10933.

[162] P.R. Benjamin, K. Staras, G. Kemenes, What roles do tonic inhibition and disinhibition play in the control of motor programs?, Front. Behav. Neurosci. 4 (2010) 30.

[163] S. Grillner, B. Robertson, The Basal Ganglia Over 500 Million Years, Curr. Biol. 26 (2016) R1088-R1100.

[164] A. Mazzoni, F.D. Broccard, E. Garcia-Perez, P. Bonifazi, M.E. Ruaro, V. Torre, On the dynamics of the spontaneous activity in neuronal networks, PLoS One. 2 (2007) e439.

[165] J. Hansson, A. Neuringer, Reinforcement of variability facilitates learning in humans, J. Exp. Anal. Behav. 110 (2018) 380393.

[166] A. Neuringer, Reinforcement and induction of operant variability, Behav. Anal. 35 (2012) 229-235.

[167] K. Wagner, A. Neuringer, Operant variability when reinforcement is delayed, Learn. Behav. 34 (2006) 111-123.

[168] A. Neuringer, Operant variability: evidence, functions, and theory, Psychon. Bull. Rev. 9 (2002) 672-705.

[169] R. Wolf, M. Heisenberg, Basic organization of operant behavior as revealed in Drosophila flight orientation, J. Comp. Physiol. A. 169 (1991) 699-705.

[170] M. Heisenberg, Flexibility in a Single Behavioral Variable of Drosophila, Learning \& Memory. 8 (2001) 1-10. https://doi.org/10.1101//m.8.1.1.

[171] M. Heisenberg, Action Selection, in: Invertebrate Learning and Memory, Elsevier, 2013: pp. 9-13.

[172] Can a fly ride a bicycle?, Philos. Trans. R. Soc. Lond. B Biol. Sci. 337 (1992) 261-269.

[173] W.D. Stahlman, W. David Stahlman, K.J. Leising, D. Garlick, A.P. Blaisdell, There Is Room for Conditioning in the Creative Process: Associative Learning and the Control of Behavioral Variability, Neuroscience of Creativity. (2013) 45-68. https://doi.org/10.7551/mitpress/9780262019583.003.0003.

[174] S. Kojima, M.H. Kao, A.J. Doupe, M.S. Brainard, The Avian Basal Ganglia Are a Source of Rapid Behavioral Variation That Enables Vocal Motor Exploration, J. Neurosci. 38 (2018) 9635-9647.

[175] K.A. Jones, A.L. Jackson, G.D. Ruxton, Prey jitters; protean behaviour in grouped prey, Behav. Ecol. 22 (2011) $831-836$. 
[176] D.A. Humphries, P.M. Driver, Protean defence by prey animals, Oecologia. 5 (1970) 285-302.

[177] N.J. Newhouse, R.B. Aiken, Protean behaviour of a neustonic insect: factors releasing the fright reaction of whirligig beetles (Coleoptera: Gyrinidae), Can. J. Zool. 64 (1986) 722-726.

[178] G.F. Miller, Protean primates: The evolution of adaptive unpredictability in competition and courtship, in: A. Whiten, R.W. Byrne (Eds.), Machiavellian Intelligence II, 1st ed., Cambridge University Press, 1997: pp. 312-340.

[179] P.M. Driver, D.A. Humphries, Protean Behaviour: The Biology of Unpredictability, Clarendon Press, 1988.

[180] P.M. Driver, D.A. Humphries, Protean displays as inducers of conflict, Nature. 226 (1970) 968-969.

[181] G. Richardson, P. Dickinson, O.H.P. Burman, T.W. Pike, Unpredictable movement as an anti-predator strategy, Proc. Biol. Sci. 285 (2018). https://doi.org/10.1098/rspb.2018.1112.

[182] S.A. Arnott, D.M. Neil, A.D. Ansell, Escape trajectories of the brown shrimp crangon crangon, and a theoretical consideration of initial escape angles from predators, J. Exp. Biol. 202 (1999) 193-209.

[183] G. Miller, D. Cliff, Protean behavior in dynamic games: arguments for the co-evolution of pursuit-evasion tactics, in: P. Husbands, J.-A. Meyer (Eds.), From Animals to Animats 3: Proceedings of the Third International Conference on Simulation of Adaptive Behavior, Bradford, 1994.

[184] D.G.R. Tervo, M. Proskurin, M. Manakov, M. Kabra, A. Vollmer, K. Branson, A.Y. Karpova, Behavioral variability through stochastic choice and its gating by anterior cingulate cortex, Cell. 159 (2014) 21-32.

[185] B. Brembs, F.D. Lorenzetti, F.D. Reyes, D.A. Baxter, J.H. Byrne, Operant reward learning in Aplysia: neuronal correlates and mechanisms, Science. 296 (2002) 1706-1709.

[186] J.P. Doucet, N.G. Bazan, Excitable membranes, lipid messengers, and immediate-early genes. Alteration of signal transduction in neuromodulation and neurotrauma, Mol. Neurobiol. 6 (1992) 407-424.

[187] F. Nadim, D. Bucher, Neuromodulation of neurons and synapses, Curr. Opin. Neurobiol. 29 (2014) 48-56.

[188] K.J. Burke Jr, K.J. Bender, Modulation of Ion Channels in the Axon: Mechanisms and Function, Front. Cell. Neurosci. 13 (2019) 221.

[189] Z. Brzosko, S.B. Mierau, O. Paulsen, Neuromodulation of Spike-Timing-Dependent Plasticity: Past, Present, and Future, Neuron. 103 (2019) 563-581.

[190] G. Jékely, The chemical brain hypothesis for the origin of nervous systems, PsyArXiv. (2020). https://psyarxiv.com/3tv7p. 